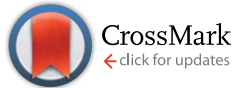

Cite this: Chem. Sci., 2016, 7, 1653

Received 4th October 2015 Accepted 27th November 2015

DOI: $10.1039 / \mathrm{c} 5 \mathrm{sc} 03766 \mathrm{~b}$

www.rsc.org/chemicalscience

\section{Highly phosphorescent platinum(II) emitters: photophysics, materials and biological applications $\uparrow$}

\author{
Kai Li, ${ }^{\text {ab }}$ Glenna So Ming Tong, ${ }^{\text {a } Q i n g y u n ~ W a n, ~}{ }^{a}$ Gang Cheng, ${ }^{\text {ab }}$ Wai-Yip Tong, ${ }^{a}$ \\ Wai-Hung Ang, ${ }^{a}$ Wai-Lun Kwong ${ }^{a}$ and Chi-Ming Che*ab
}

In recent years a blossoming interest in the synthesis, photophysics and application of phosphorescent Pt(॥) complexes, particularly on their uses in bioimaging, photocatalysis and phosphorescent organic lightemitting diodes (OLEDs), has been witnessed. The superior performance of phosphorescent $\mathrm{Pt}\left({ }_{\mathrm{I}}\right)$ complexes in these applications is linked to their diverse spectroscopic and photophysical properties, which can be systematically modulated by appropriate choices of auxiliary ligands. Meanwhile, an important criterion for the practical application of phosphorescent metal complexes is their stability which is crucial for biological utilization and industrial OLED applications. Taking both the luminescence properties and stability into consideration, chelating ligands having rigid scaffolds and with strong $\sigma$ donor atoms are advantageous for the construction of highly robust phosphorescent Pt(॥) complexes. The square-planar coordination geometry endows Pt(॥) complexes with the intriguing spectroscopic and photophysical properties associated with their intermolecular interactions in both the ground and excited states. In this article, we discuss the design and synthesis of phosphorescent Pt(॥) complexes with elaboration on the effects of ligands on the structure and luminescence properties. Based on their photophysical and emission properties, we intend to shed light on the great promise of highly robust phosphorescent Pt(॥) emitters in an array of applications from molecular materials to biosensors.

\section{Introduction}

Phosphorescent transition metal complexes are distinct from pure organic luminophores due to their characteristic long emission lifetime, large absorption-emission Stokes shift, and tuneable excited states. The efficient phosphorescence from transition metal complexes at room temperature is attributed to the heavy atom effect that induces strong spin-orbit coupling (SOC), facilitating both fast intersystem crossing (ISC) and the formally spin-forbidden triplet radiative decay. ${ }^{\mathbf{1 , 2}}$ In the literature, there are numerous reports on the photophysical and photochemical properties of transition metal complexes, particularly those of $\mathrm{Ru}(\mathrm{II}), \mathrm{Ir}(\mathrm{III})$, and $\mathrm{Pt}(\mathrm{II}) .^{3-7}$ Platinum, being a third-row transition element, has the second largest SOC constant. In contrast to $\mathrm{d}^{6} \mathrm{Ru}$ (II) and $\mathrm{Ir}(\mathrm{III})$ complexes that have an octahedral coordination geometry, $\mathrm{d}^{8} \mathrm{Pt}(\mathrm{II})$ complexes usually adopt a square planar coordination geometry with open axial coordination sites

${ }^{a}$ State Key Laboratory of Synthetic Chemistry, Institute of Molecular Functional Materials, HKU-CAS Joint Laboratory on New Materials and Department of Chemistry, The University of Hong Kong, Pokfulam Road, Hong Kong, China. E-mail: cmche@hku.hk

${ }^{b} H K U$ Shenzhen Institute of Research and Innovation, Shenzhen 518053, China

$\dagger$ Electronic supplementary information (ESI) available. See DOI: $10.1039 / \mathrm{c} 5 \mathrm{sc} 03766 \mathrm{~b}$ allowing for structural distortion, inner sphere substrate binding, and intermolecular interactions, all of which can significantly alter the ground state and excited state properties. ${ }^{8}$ We and others have been working to develop new classes of phosphorescent $\mathrm{Pt}(\mathrm{II})$ complexes and explore their applications in

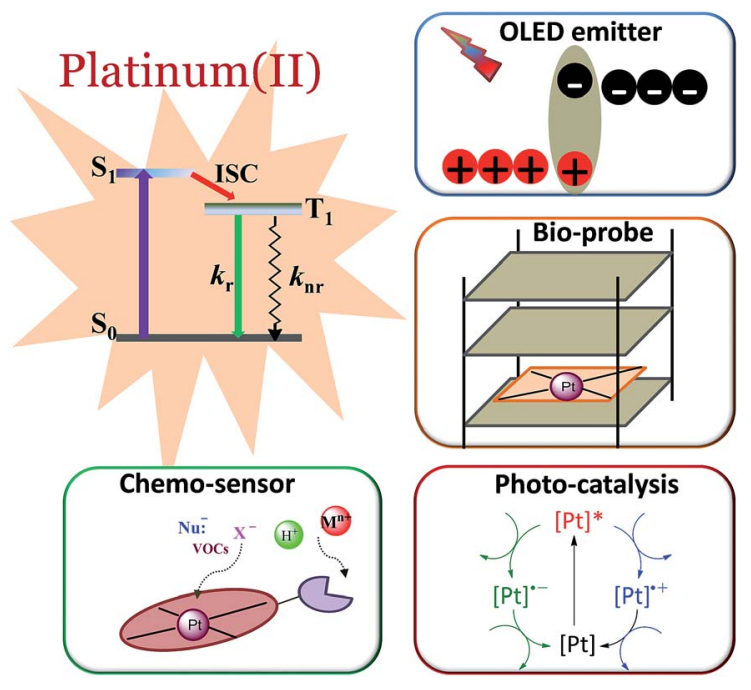

Fig. 1 Various applications of phosphorescent Pt(॥) complexes. 
luminescent chemosensing, ${ }^{\text {9-12 }}$ photocatalysis, ${ }^{13-16}$ optical limiting, ${ }^{17}$ bioimaging, ${ }^{18-21}$ and organic light-emitting diodes (OLEDs) 22 (Fig. 1).

State-of-the-art phosphorescent OLEDs based on Ir(III) and $\mathrm{Pt}(\mathrm{II})$ emitters have exhibited high efficiencies with an external quantum efficiency (EQE) $>20 \%$. However, one of the obstacles in the commercialization of phosphorescent OLEDs is the stability of the various materials used in the device fabrication. Hence, a high robustness of phosphorescent transition metal complexes is essential for enabling their practical application. In this regard, triplet emitters should be (1) tolerant to thermal deposition during device fabrication, (2) resistant to structural rearrangement as encountered in some Ir(III)-OLED emitters during thermal treatment ${ }^{23-25}$ and (3) stable against chemical degradation that leads to device operational aging. ${ }^{26}$ As bioimaging agents, the phosphorescent metal complexes should preferably be kinetically inert against ligand-exchange reactions or biological reduction under physiological conditions. ${ }^{18}$ In photocatalysis, the metal complex acting as the photosensitizer would have to be stable against photobleaching and solvent-induced decomposition in order to afford a high product turnover. ${ }^{27}$

The robustness of a phosphorescent metal complex is a crucial issue because the presence of electron(s) in the metalligand anti-bonding $\mathrm{d}_{\sigma}$ orbitals (for $\mathrm{d}^{6}$ and $\mathrm{d}^{8}$ electronic configuration), either through photoexcitation or thermal population, will decrease the strength of the $\mathrm{M}-\mathrm{L}$ bond, resulting in its rupture. It is well-documented that the photosubstitution/ photodissociation of $\left[\mathrm{Ru}(\mathrm{bpy})_{3}\right]^{2+}$ (bpy $=2,2^{\prime}$-bipyridine) in solution occurs via thermally populated metal-centred (MC) dd states. ${ }^{28,29}$ The rupture of Ir-L bonds via strongly structurally distorted $d-d$ states has been reported to account for the degradation of Ir(III) dopants in OLEDs. ${ }^{26}$

In this perspective, we describe the factors that affect the non-radiative decay rate and stability of luminescent $\mathrm{Pt}$ (II) complexes, followed by a discussion of the recent advances made in phosphorescent Pt(II) complexes which display high emission efficiency and/or high stability. In particular, the latest reports on luminescent $\mathrm{Pt}(\mathrm{II})$ complexes supported by tetradentate ligands are summarized. Based on experimental findings and theoretical calculations, we try to correlate superior emission properties and robustness with structure in selected classes of phosphorescent Pt(II) complexes. In addition to being used as phosphorescent OLED dopant materials, the selfassembly and bioimaging applications of luminescent $\mathrm{Pt}$ (II) complexes are highlighted.

\section{Design principles for highly robust, strongly emissive Pt(II) complexes}

\subsection{Factors affecting phosphorescence quantum yield}

The phosphorescence quantum yield $\left(\phi_{\mathrm{P}}\right)$ of the triplet excited state is determined by the radiative $\left(k_{\mathrm{r}}\right)$ and non-radiative $\left(k_{\mathrm{nr}}\right)$ decay rates:

$$
\phi_{\mathrm{P}}=\frac{k_{\mathrm{r}}}{k_{\mathrm{r}}+k_{\mathrm{nr}}}
$$

Among all the variables, suppressing the non-radiative decay rate $k_{\mathrm{nr}}$ is instrumental to achieving efficient phosphorescence. To this end, two main approaches have been employed: (1) decreasing the excited state structural distortion, and (2) altering the coordination environment so as to destabilize the metal-centred (MC) ligand-field excited states.

2.1.1 Minimizing excited state structural distortion. Unlike $\mathrm{d}^{6} \mathrm{Ru}(\mathrm{II})$ and $\mathrm{Ir}(\mathrm{III})$ complexes that have an octahedral coordination environment, Pt(II) complexes usually adopt a square planar coordination geometry. The vacant axial coordination site(s) associated with square planar coordination geometry renders the excited state more flexible in undergoing structural reorganization, thus facilitating non-radiative decay. In addition, while the emitting triplet excited states of $\mathrm{Ru}(\mathrm{II})$ and $\operatorname{Ir}(\mathrm{III})$ complexes are usually ${ }^{3}$ MLCT in nature (MLCT $=$ metal-toligand charge transfer), the emissions of $\mathrm{Pt}(\mathrm{II})$ complexes usually have a ${ }^{3}$ MLCT character mixed with a significant ligand character, for instance, from intraligand charge transfer $\left({ }^{3}\right.$ ILCT $)$ and ligand-centred ${ }^{3} \pi-\pi^{*}$ excited states. Therefore, one possible avenue to diminish $k_{\mathrm{nr}}$ is to design ligands for which the excited state structural distortion is small. Specifically, the so-called Huang-Rhys factor $S$ serves to quantify the structural distortion $\Delta Q$ of the excited state with respect to the ground state. If $S=0$, the excited state and the ground state have the same equilibrium geometries and only a sharp peak corresponding to a $0-0$ transition is observed (Fig. 2). With an increase in $\Delta Q$ and hence an increase in $S$, a vibronic
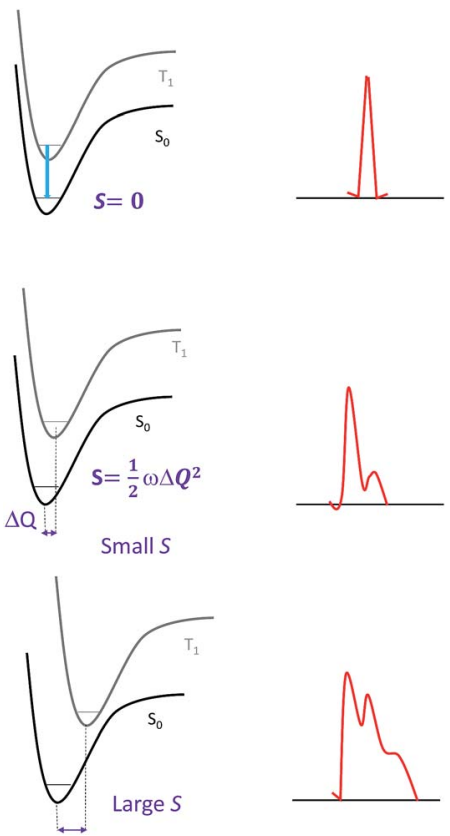

Fig. 2 Correlations between the structural distortion of the triplet excited state with respect to the ground state and the emission spectrum: (top) sharp line emission with no structural distortion $(S=$ $0)$; (middle) narrow bandwidth spectrum with a small structural distortion (i.e., $S$ is small); and (bottom) broad bandwidth spectrum yet with the vibrational signature of a larger structural distortion (i.e., $S$ is large); for an even larger $S$, only a broadband spectrum is observed. 
progression is observed (Fig. 2); the relative intensity of the 00 line and the first vibronic peak $1-0$ are given by $S$ :

$$
S=\frac{I_{1-0}}{I_{0-0}}
$$

Since the overall emission bandwidth is affected by the intensity of all the vibronic progressions, a smaller $S$ also implies a spectrum of narrow bandwidth and higher colour purity. Thus, complexes with highly rigid scaffolds are advantageous for developing luminescent materials with high emission quantum efficiencies.

Spectroscopic and computational studies have revealed that the non-radiative decay rate of luminescent pincer-type cyclometalated Pt(II) complexes can be profoundly affected by the ligands coordinated to $\mathrm{Pt}(\mathrm{II})$. As depicted in Fig. 3, there is usually a significant structural distortion from a coplanar ground state geometry to a bent conformation in the $\mathrm{T}_{1}$ excited state for the cyclometalated Pt(II) complexes that are non- or weakly emissive..$^{30-32}$ Computational studies revealed that the quasi-degeneracy of the HOMO and $\mathrm{H}-1$ orbitals and steric strain between the cyclometalated and ancillary ligands contribute to this type of excited state structural distortion that leads to very fast non-radiative decay. ${ }^{31,32}$ It has been pointed out that, in the design of efficient phosphorescent Pt(II) emitters, the relative dispositions of coordinating donor atoms to the $\mathrm{Pt}(\mathrm{II})$ ion and the site of $\pi$-conjugation should be taken into consideration. ${ }^{31,32}$

2.1.2 Altering ligand-field splitting. Another tactic to decrease $k_{\mathrm{nr}}$ is pushing the $\mathrm{MC}{ }^{3} \mathrm{~d}-\mathrm{d}$ excited states well above the emitting triplet excited state. The thermal population of the strongly anti-bonding $5 \mathrm{~d}_{x^{2}-y^{2}}$ orbital decreases the Pt-L bonding character, thereby providing an efficient non-radiative decay channel via severe structural distortions in the excited state. A common approach is to use strong $\sigma$-donor ligands, such as C-deprotonated cyclometalated ligands, N-heterocyclic carbenes (NHCs), and phenoxide ions.

\subsection{Factors affecting the stability of phosphorescent metal complexes}

Degradation of phosphorescent transition metal complexes usually occurs via $\mathrm{M}-\mathrm{L}$ bond rupture. The tactics to reduce the propensity of M-L bond dissociation lie in (1) strengthening M-L bonds using strong $\sigma$-donor ligands and (2) using multidentate ligands. In general, transition metal complexes supported by multidentate ligands are more stable than those with monodentate ligands having comparable donor strength (termed the chelate effect); this is the result of the entropy effect

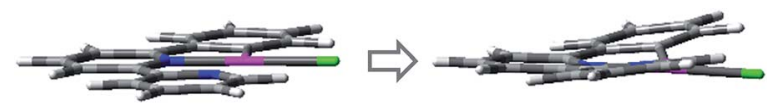

Fig. 3 Optimized geometries of the ground state $\mathrm{S}_{0}$ (left) and the lowest triplet excited state $T_{1}$ (right) of $\left[\mathrm{Pt}\left(\mathrm{C}^{\wedge} \mathrm{N}^{\wedge} \mathrm{N}\right) \mathrm{Cl}\right] \mathbf{4}$ (adapted with permission from ref. 31. Copyright 2009, Wiley-VCH Verlag GmbH \& Co. KGaA).

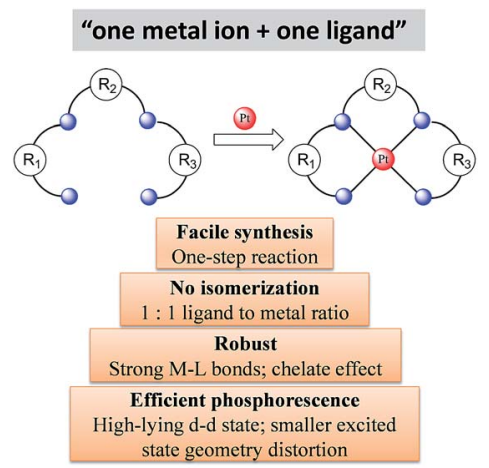

Scheme 1 Illustration of the "one metal ion + one ligand" approach.

in chelation reactions. ${ }^{33}$ In addition, the stability of transition metal complexes is influenced by the chelate ring size: 6membered rings confer higher stability than 5-membered ones. $^{33}$

\subsection{Multidentate ligands for high efficiency and stability}

Considering the structural factors that affect emission efficiency, colour purity, and robustness, rigid multidentate ligand scaffolds containing strong $\sigma$-donor atoms are beneficial for the development of highly robust phosphorescent Pt(II) complexes (Scheme 1). This design principle is reminiscent of the $\mathrm{Ru}$ (II) polypyridyl complexes supported by "cage" or "hemicage" ligands, which have been shown to display superior emission properties and high photostability against light-induced substitution and decomposition reactions. ${ }^{28,29,34,35}$ In the literature, there are few examples of the "one metal ion + one ligand" approach to develop luminescent $\mathrm{d}^{6} \operatorname{Ir}$ (III) complexes. ${ }^{36}$ This may be due to the formidable challenges in synthesizing chemically inert, rigid hexadentate ligand scaffolds. In this regard, $\mathrm{Pt}(\mathrm{II})$ complexes are advantageous over $\mathrm{d}^{6}$ octahedral metal complexes because tetradentate ligand scaffolds are relatively easy to construct and modify (Scheme 1). Indeed, the recently developed Pt(II) complexes supported by tetradentate ligands have shown impressive emission efficiencies $\left(\phi_{\mathrm{P}} \sim 1\right)$ and exceptional thermal stability $\left(T_{\mathrm{d}}>400{ }^{\circ} \mathrm{C}\right) \cdot{ }^{37}$

\section{Advances in luminescent Pt(II) complexes}

In this section, we describe the structures and emission properties of various types of Pt(II) complexes which display high emission efficiency and/or high stability. Their pertinent photophysical data are summarized in Tables 1 and 2. Additionally, the performances of OLEDs doped with selected examples of these Pt(II) emitters are discussed.

\subsection{Luminescent Pt(II) complexes containing bidentate ligands}

Homoleptic bis-cyclometalated Pt(II) complexes were reported as early as 1984 by von Zelewsky et al. ${ }^{38-40}$ This type of complex is 
Table 1 Physical data of the Pt(॥) complexes containing bidentate or terdentate cyclometalated ligands

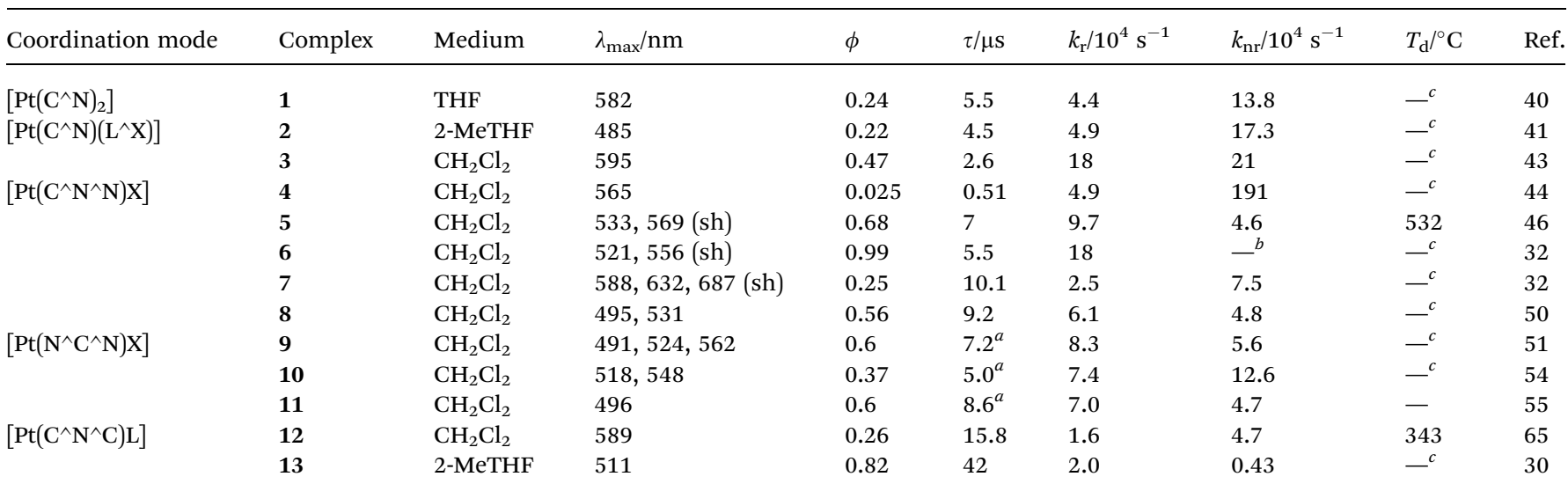

${ }^{a}$ The lifetime $\tau_{0}$ at infinite dilution determined from the linear variation of the observed emission decay rate constant, $k_{\mathrm{obs}}$, as a function of the concentration of the complex. ${ }^{b}$ Value too low to be reported. ${ }^{c}$ Value not available from the literature.

known for its photochemical reactivity towards halogenated hydrocarbons. For example, the strongly orange light-emitting $\mathrm{Pt}(\text { thpy })_{2}$ (1) $(\phi=0.24$ in THF) underwent an oxidative addition reaction with halogen-containing molecules, affording the corresponding $\mathrm{Pt}(\mathrm{Iv})$ complexes which show blue-shifted phosphorescence. ${ }^{40}$ In view of the harsh conditions required for their preparation and their intriguing photolability, the phosphorescent bis-cyclometalated Pt(II) complexes have been sparsely used as robust emitters. Alternatively, a number of heteroleptic cyclometalated $\mathrm{Pt}(\mathrm{II})$ complexes with the formula $\left[\mathrm{Pt}\left(\mathrm{C}^{\wedge} \mathrm{N}\right)(\mathrm{a}-\right.$ cac)] ( $\mathrm{C}^{\wedge} \mathrm{N}$ denotes $\mathrm{C}$-deprotonated 2-phenylpyridyl ligands and their derivatives; acac denotes deprotonated acetylacetone) have been reported and show intense phosphorescence in solution at room temperature. ${ }^{41,42}$ For example, 2 is strongly emissive with $\lambda_{\max }=485 \mathrm{~nm}(\phi=0.22)$ in 2-methyltetrahydrofuran (2MeTHF). ${ }^{41}$ It was reported that modification of the substitution on the cyclometalating $\mathrm{C}^{\wedge} \mathrm{N}$ ligand could tune the emission energy to cover the visible spectral region.

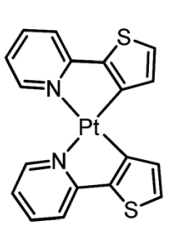

1

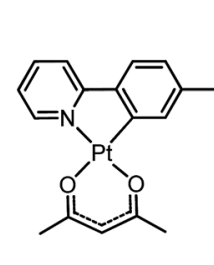

2

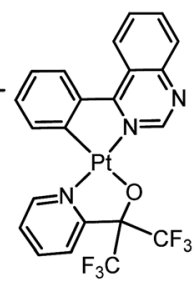

3
In the literature, heteroleptic cyclometalated $\mathrm{Pt}(\mathrm{II})$ and $\operatorname{Ir}(\mathrm{III})$ complexes, i.e., $\left[\mathrm{Pt}\left(\mathrm{C}^{\wedge} \mathrm{N}\right)\left(\mathrm{L}^{\wedge} \mathrm{X}\right)\right]$ and $\left[\operatorname{Ir}\left(\mathrm{C}^{\wedge} \mathrm{N}\right)_{2}\left(\mathrm{~L}^{\wedge} \mathrm{X}\right)\right]$, have usually been used in the design of high performance triplet emitters. ${ }^{5,7}$ These complexes could be obtained from chloro-bridged $\left[\operatorname{Pt}\left(\mathrm{C}^{\wedge} \mathrm{N}\right)(\mu-\mathrm{Cl})\right]_{2}$ or $\left[\operatorname{Ir}\left(\mathrm{C}^{\wedge} \mathrm{N}\right)_{2}(\mu-\mathrm{Cl})\right]_{2}$ dinuclear intermediates. Hence, modification of the cyclometalated and ancillary $L^{\wedge} X$ moieties could be performed to systematically tune the physical and photophysical properties of these metal emitters. However, unlike the extensive reports on $\left[\operatorname{Ir}\left(\mathrm{C}^{\wedge} \mathrm{N}\right)_{2}\left(\mathrm{~L}^{\wedge} \mathrm{X}\right)\right]$ with $\mathrm{L}^{\wedge} \mathrm{X}$ covering diverse mono-anionic bidentate ligands, ${ }^{5,7}$ only deprotonated acetylacetone (acac) and its derivatives are utilized as $\mathrm{L}^{\wedge} \mathrm{X}$ ligands in the development of luminescent Pt(II) complexes of the type $\left[\operatorname{Pt}\left(\mathrm{C}^{\wedge} \mathrm{N}\right)\left(\mathrm{L}^{\wedge} \mathrm{X}\right)\right]{ }^{42}$ At this juncture, it should be noted that complex 3, bearing 2-pyridyl hexafluoro-propoxide as the ancillary ligand, was reported to exhibit a high emission quantum yield of 0.47 $\left(\lambda_{\max }=595 \mathrm{~nm}\right)$ in $\mathrm{CH}_{2} \mathrm{Cl}_{2} \cdot{ }^{43}$ This finding highlights the promising prospect that phosphorescent $\left[\operatorname{Pt}\left(\mathrm{C}^{\wedge} \mathrm{N}\right)\left(\mathrm{L}^{\wedge} \mathrm{X}\right)\right]$ complexes have and indicates that they deserve further attention.

\subsection{Luminescent Pt(II) complexes containing a terdentate C- deprotonated ligand}

In 1999, Che and co-workers described luminescent pincer-type Pt(II) complexes supported by C-deprotonated 6-aryl-2,2'-bipyridine ligands. ${ }^{44}$ Compared to $[\mathrm{Pt}(\operatorname{trpy}) \mathrm{Cl}]^{+}$(trpy $=2,2^{\prime}: 6^{\prime}, 2^{\prime \prime}$-terpyridine), which is non-emissive under ambient conditions, complex 4 is emissive in $\mathrm{CH}_{2} \mathrm{Cl}_{2}(\phi=0.025)$ at room temperature, with the lowest triplet excited state having a ${ }^{3} \mathrm{MLCT}$ character. It was suggested that the covalent $\mathrm{Pt}-\mathrm{C}$ bond is the root cause for the enhanced emission properties of this complex in solution. Modification of either the $\mathrm{C}^{\wedge} \mathrm{N}^{\wedge} \mathrm{N}$ moiety or ancillary ligand has led to a number of luminescent $\mathrm{Pt}(\mathrm{II})$ complexes with improved emission quantum yields and enhanced stability. ${ }^{45,46}$ For example, by extending $\pi$-conjugation of the Cdeprotonated $\left(\mathrm{C}^{\wedge} \mathrm{N}^{\wedge} \mathrm{N}\right)$ moiety, strongly luminescent $5\left(\lambda_{\max }=\right.$ $533 \mathrm{~nm}$ and $\phi=0.68$ in $\mathrm{CH}_{2} \mathrm{Cl}_{2}$ ) was prepared ${ }^{46}$ Computational studies revealed that the extended $\pi$-conjugation of the cyclometalated ligand in $\mathbf{5}$ removes the quasi-degeneracy of the HOMO and $\mathrm{H}-1$ orbitals, and hence the structural distortion between the $\mathrm{T}_{1}$ excited state and ground state is smaller when compared to that of 4 . This accounts for the low $k_{\mathrm{nr}}$ value of 5 in comparison to $4\left(k_{\mathrm{nr}}=1.9 \times 10^{6} \mathrm{~s}^{-1}\right.$ for 4 and $4.6 \times 10^{4} \mathrm{~s}^{-1}$ for $5) .{ }^{31}$ It is of note that, because of the rigid $\pi$-conjugated terdentate cyclometalated ligand, $\mathbf{5}$ has a high thermal stability with a decomposition temperature $\left(T_{\mathrm{d}}\right)$ of $532{ }^{\circ} \mathrm{C}$ in $\mathrm{N}_{2}$. Using 5 as a light-emitting material, a high-performance yellowishgreen OLED was fabricated with a maximum brightness of $63000 \mathrm{~cd} \mathrm{~m}^{-2}$. Che and co-workers also reported an efficient 
white OLED (WOLED) by combining emissions from a blue fluorescent material and a green-yellow emitting analogue of $\mathbf{5}$ in which the ${ }^{t} \mathrm{Bu}$ groups were changed into $\mathrm{CF}_{3} .{ }^{47}$ The device having dual emitting layers exhibited a balanced white-light with a CIE of $(0.30,0.32)$. The maximum EQE reached $11.8 \%$. Very recently, Che and co-workers reported that $6\left(\lambda_{\max }=521\right.$ $\mathrm{nm}$ ) displays a phosphorescence efficiency of almost one in room temperature solution. ${ }^{32}$ Computational studies revealed that 6 shows the smallest structural distortion from $S_{0}$ to $T_{1}$ along the high-frequency normal modes of the complexes studied therein. The excited state geometry distortion was found to be highly dependent on the site of $\pi$-conjugation and nature of the additional ancillary ligand. A yellowish-green OLED doped with 6 showed a maximum EQE of $22.8 \%$, which is among the highest values ever reported for OLEDs with $\mathrm{Pt}(\mathrm{II})$ dopants. With a thiophene-containing $\pi$-conjugated ligand, complex 7 has an emission with $\lambda_{\max }=588 \mathrm{~nm}$ in $\mathrm{CH}_{2} \mathrm{Cl}_{2} \cdot{ }^{32} \mathrm{An}$ efficient red-emitting OLED fabricated using 7 as the dopant showed a maximum EQE of $22.1 \%$, which is comparable to the best values of red-emitting OLEDs based on Ir(III) complexes. ${ }^{48}$ The pincer-type cyclometalated $\mathrm{Pt}(\mathrm{II})$ complexes have been employed as photosensitizers or photocatalysts for solar energy conversions. Fu and co-workers showed that $\left[\mathrm{Pt}\left(\mathrm{C}^{\wedge} \mathrm{N}^{\wedge} \mathrm{NPhMe}\right)\right.$ $\mathrm{Cl}]\left(\mathrm{HC}^{\wedge} \mathrm{N}^{\wedge} \mathrm{NPhMe}=4\right.$-( $p$-tolyl)-6-phenyl-2, $2^{\prime}$-bipyridine) was an effective photosensitizer for hydrogen evolution from water and afforded a much higher turnover number than its terpyridyl analogue under the same experimental conditions. ${ }^{49}$ Complex 6 has been examined by Che as a photocatalyst for visible lightinduced reductive $\mathrm{C}-\mathrm{C}$ bond formation reactions (Scheme 2). ${ }^{32}$ With diisopropylethylamine ( $\left.{ }^{\mathrm{i}} \mathrm{Pr}_{2} \mathrm{NEt}\right)$ as a sacrificial electron donor in $\mathrm{CH}_{3} \mathrm{CN}$, and after 4-8 hours of irradiation using a blue LED, a series of alkyl bromides underwent intramolecular C-C bond formation with conversions and yields of up to $99 \%$ and $78 \%$, respectively. This complex also catalysed the light-induced intermolecular $\mathrm{C}-\mathrm{C}$ bond formation from benzyl chloride.
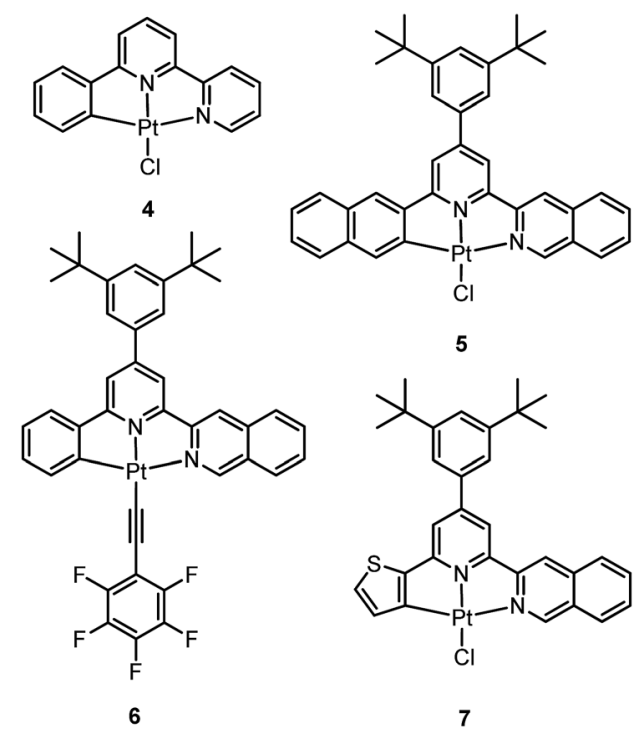

Huo and co-workers reported the structural modification of a terdentate C-deprotonated cyclometalated ligand resulting in the change of its $\left[\operatorname{Pt}\left(\mathrm{C}^{\wedge} \mathrm{N}^{\wedge} \mathrm{N}\right)\right]$ motif from having a fused 5,5membered metallacycle (as in 4-7) to having a 5,6-membered one (as in 8). ${ }^{50}$ Complex 8 exhibits substantially improved phosphorescence ( $\phi=0.56$ and $\tau=9.2 \mu \mathrm{s}$ in $\mathrm{CH}_{2} \mathrm{Cl}_{2}$ ) compared to its fused 5,5 analogue, $\left[\operatorname{Pt}^{\wedge}\left(\mathrm{C}^{\wedge} \mathrm{N}^{\wedge} \mathrm{N}\right)(\mathrm{C} \equiv \mathrm{CPh})\right](\phi=0.04$ and $\tau$ $=0.4 \mu \mathrm{s}$ in $\left.\mathrm{CH}_{2} \mathrm{Cl}_{2}\right)($ Chart S1, ESI $\dagger){ }^{45}$ The substantial difference in the $k_{\mathrm{nr}}$ values of both complexes $\left(k_{\mathrm{nr}}=4.8 \times 10^{4} \mathrm{~s}^{-1}\right.$ for $8 v s$. $2.4 \times 10^{6} \mathrm{~s}^{-1}$ for $\left.\left[\mathrm{Pt}\left(\mathrm{C}^{\wedge} \mathrm{N}^{\wedge} \mathrm{N}\right)(\mathrm{C} \equiv \mathrm{CPh})\right]\right)$ reveals that the phosphorescence efficiency is strongly affected by the non-radiative decay rate constant. On the one hand, the slower non-radiative decay rate of $\mathbf{8}$ is probably due to the stronger donor strength of $8{ }^{50}$ while on the other hand, computational studies have shown that the emitting triplet excited state of $\left[\mathrm{Pt}\left(\mathrm{C}^{\wedge} \mathrm{N}^{\wedge} \mathrm{N}\right)(\mathrm{C} \equiv \mathrm{CPh})\right]$ is $\mathrm{a}^{3}\left[\pi(\mathrm{C} \equiv \mathrm{CPh}) \rightarrow \pi^{*}\left(\mathrm{C}^{\wedge} \mathrm{N}^{\wedge} \mathrm{N}\right)\right]$ ligand-to-ligand charge transfer (LLCT) mixed with ${ }^{3}\left[\mathrm{~d} \pi(\mathrm{Pt}) \rightarrow \pi^{*}\left(\mathrm{C}^{\wedge} \mathrm{N}^{\wedge} \mathrm{N}\right)\right]$ (MLCT), and that of 8 is ${ }^{3} \pi-\pi^{*}\left(\mathrm{C}^{\wedge} \mathrm{N}\right)$ mixed with ${ }^{3}\left[\mathrm{~d} \pi(\mathrm{Pt}) \rightarrow \pi^{*}\left(\mathrm{C}^{\wedge} \mathrm{N}\right)\right]$ (Fig. S1, ESI $\dagger$ ). These calculations are consistent with the experimental finding that $\left[\operatorname{Pt}\left(\mathrm{C}^{\wedge} \mathrm{N}^{\wedge} \mathrm{N}\right)(\mathrm{C} \equiv \mathrm{CPh})\right]$ and $\mathbf{8}$ display structureless and vibronic-structured emission profiles, respectively. As the emissive excited state of $\left[\mathrm{Pt}\left(\mathrm{C}^{\wedge} \mathrm{N}^{\wedge} \mathrm{N}\right)(\mathrm{C} \equiv \mathrm{CPh})\right]$ involves distortion of the $\mathrm{C} \equiv \mathrm{C}$ bond while that of $\mathbf{8}$ does not, the presence of an additional effective high-frequency accepting mode, $\omega_{\mathrm{C}} \equiv \mathrm{C}$, would lend the former complex a faster non-radiative decay rate (see details in the ESI $\dagger$ ). This difference in the nature of the $\mathrm{T}_{1}$ excited state is attributed to the presence of an additional amine bridge in 8 that causes the $\mathrm{C}^{\wedge} \mathrm{N}$ moiety and pyridyl ring to be non-planar to each other, while the C-deprotonated $\mathrm{C}^{\wedge} \mathrm{N}^{\wedge} \mathrm{N}$ cyclometalated ligand has a relatively planar geometry in the case of $\left[\mathrm{Pt}\left(\mathrm{C}^{\wedge} \mathrm{N}^{\wedge} \mathrm{N}\right)(\mathrm{C} \equiv \mathrm{CPh})\right]$ (Fig. S2, ESI $\dagger$ ). Moreover, as stated by the energy-gap law, the lower emission energy of $\left[\mathrm{Pt}\left(\mathrm{C}^{\wedge} \mathrm{N}^{\wedge} \mathrm{N}\right)(\mathrm{C} \equiv \mathrm{CPh})\right]$ may also contribute to the observed faster non-radiative decay rate.

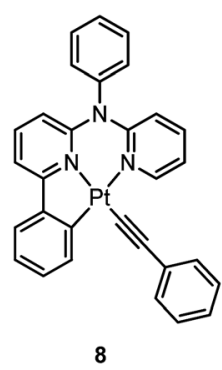

Williams and co-workers described Pt(II) complexes ( 9 and its derivatives) supported by terdentate cyclometalated ligands derived from C-deprotonated 1,3-bis(2-pyridyl)benzene $\left(\mathrm{N}^{\wedge} \mathrm{C}^{\wedge} \mathrm{N}\right)$ ligands. ${ }^{51} \mathrm{~A}$ high emission efficiency of 0.6 was recorded for 9 in $\mathrm{CH}_{2} \mathrm{Cl}_{2}$ and the emitting triplet excited state has been characterized to be metal-perturbed ${ }^{3} \mathrm{IL}$ ( $\mathrm{IL}=$ intraligand) in nature. Compared to $\left[\mathrm{Pt}^{(}\left(\mathrm{C}^{\wedge} \mathrm{N}^{\wedge} \mathrm{N}\right) \mathrm{Cl}\right](\mathbf{4})$, shorter $\mathrm{Pt}-\mathrm{C}$ bonds were observed for $\mathbf{9}$ and its derivatives. ${ }^{51,52}$ This may result in $\mathbf{9}$ having a higher-lying $\mathrm{d}-\mathrm{d}$ excited state. The finding of the emission lifetime to be insensitive to temperature rules out the possibility of a non-radiative decay pathway occurring via a dd state. ${ }^{53}$ The $\left[\mathrm{Pt}\left(\mathrm{N}^{\wedge} \mathrm{C}^{\wedge} \mathrm{N}\right) \mathrm{Cl}\right]$ complexes show a strong tendency to undergo excimer formation at elevated concentrations in solution, and aggregation and/or excimer formation in the solid state. Taking advantage of this feature, modification of either 

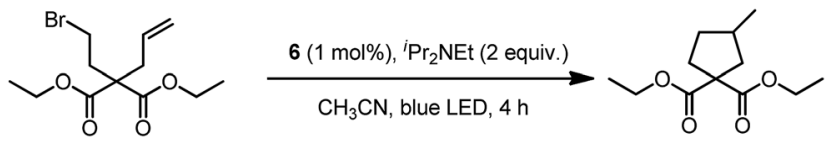

Scheme 2

the cyclometalating moiety or variation of the fourth auxiliary ligand can tune the energy of frontier molecular orbitals and/or perturb the extent of intermolecular interactions, leading to a shift in the emission to the near-infrared (NIR) region. For instance, attaching electron-withdrawing $-\mathrm{CF}_{3}$ groups stabilizes the pyridyl-localized LUMO of $\mathbf{1 0}$ and hence its excimeric emission occurs at a low energy of $756 \mathrm{~nm}$ in $\mathrm{CH}_{2} \mathrm{Cl}_{2} \cdot{ }^{54}$ Coordination of $\mathrm{SCN}^{-}$to $\mathrm{Pt}(\mathrm{II})$, as in the case of 11, does not affect the excited state energy in comparison to its chloride counterpart, but alters the solid-state packing, resulting in a shorter $\mathrm{Pt} \cdots \mathrm{Pt}$ contact of $3.3 \AA$ A . As a consequence, an OLED based on a neatfilm of 11 shows EL at $855 \mathrm{~nm} \cdot{ }^{55}$ In addition to the promising NIR emission due to aggregation or excimer formation, cyclometalated pincer-type $\mathrm{Pt}(\mathrm{II})$ complexes are also promising candidate materials for single-dopant WOLEDs through a combination of both their monomeric blue-to-green emission and excimeric red emission (vide infra). ${ }^{56-58}$
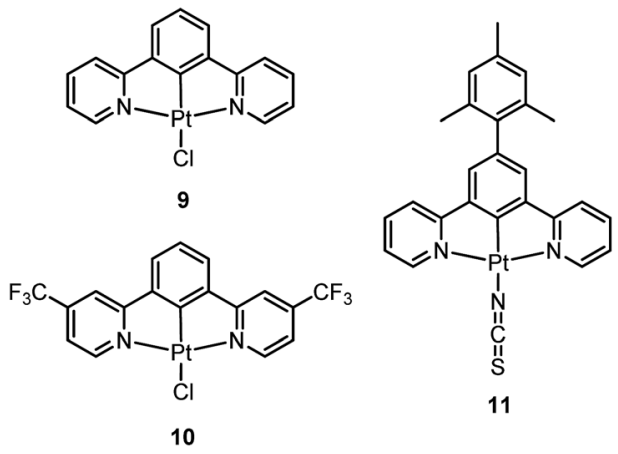

Pt(II) complexes supported by doubly C-deprotonated 2,6diphenylpyridine $\left(\mathrm{C}^{\wedge} \mathrm{N}^{\wedge} \mathrm{C}\right)$ ligands constitute another class of cyclometalated $\mathrm{Pt}(\mathrm{II})$ complexes which possess rich photophysical properties. ${ }^{59-64}$ Despite the presence of two covalent Pt$\mathrm{C}$ bonds, most of the $\left[\mathrm{Pt}\left(\mathrm{C}^{\wedge} \mathrm{N}^{\wedge} \mathrm{C}\right) \mathrm{L}\right]$ type complexes are nonemissive or weakly emissive in solution at room temperature. Computational studies revealed that these complexes undergo significant structural distortions upon shifting from $S_{0}$ to $T_{1}$ state. ${ }^{31}$ In 2012, Che and co-workers reported the first examples of organoplatinum(II) complexes bearing functionalized $\left(\mathrm{C}^{\wedge} \mathrm{N}^{\wedge} \mathrm{C}\right)$ ligands that are emissive in solution at room temperature (e.g., $\phi=0.26$ for 12$).{ }^{65}$ The emission switch-on property is achieved by extending the $\pi$-conjugation of the $\left(\mathrm{C}^{\wedge} \mathrm{N}^{\wedge} \mathrm{C}\right)$ ligand, thereby shifting the lowest electronic excited states to be predominantly ${ }^{3} \mathrm{IL}$ in nature. Because of the more rigid ligand framework, the excited state structural distortion of the new emitters is greatly reduced. High thermal stability $\left(T_{\mathrm{d}}>300^{\circ} \mathrm{C}\right)$ renders 12 a suitable dopant for OLED applications; a red OLED with CIE coordinates of $(0.65,0.35)$ was fabricated and a maximum EQE of $12.6 \%$ was obtained. Very recently, Yersin et al. developed a brightly luminescent $\mathrm{Pt}$ (II) complex $\mathbf{1 3}$ ( $\phi=$ 0.82 in 2-MeTHF) which is supported by a bulky and rigid carboranyl-phenylpyridine ligand. ${ }^{30}$ Photophysical studies revealed an exceptionally small non-radiative decay rate constant that is in the order of $10^{3} \mathrm{~s}^{-1}$. DFT calculations showed that no bent conformation, which is commonly encountered in other nonemissive $\left[\mathrm{Pt}\left(\mathrm{C}^{\wedge} \mathrm{N}^{\wedge} \mathrm{C}\right) \mathrm{X}\right](\mathrm{X}=$ auxiliary ligand $)$ complexes, can be observed in the $T_{1}$ excited state of $\mathbf{1 3}$, thereby significantly decreasing the non-radiative decay rate.

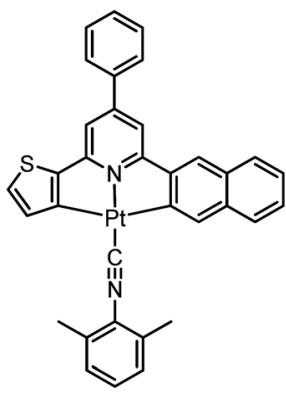

12

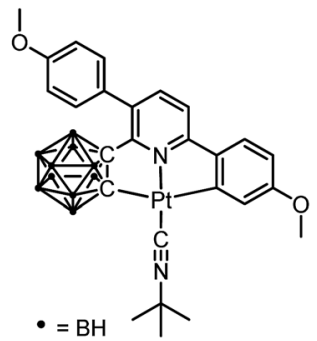

13

\subsection{Luminescent Pt(II) complexes supported by a tetradentate ligand}

$\mathrm{Pt}(\mathrm{II})$ porphyrin complexes are well-known to be robust phosphorescent emitters as a result of the rigid macrocyclic porphyrin ligand scaffold. With an extended $\pi$-conjugated porphyrin ligand, these complexes display red or NIR ${ }^{3} \mathrm{IL}$ emission with very long lifetimes. ${ }^{66-69}$ In recent years, there has been a surge of interest to develop luminescent $\mathrm{Pt}(\mathrm{II})$ complexes supported by non-porphyrin tetradentate ligands. By judiciously designing the tetradentate ligand, the emission energy can be tuned throughout the entire visible spectral region. This type of Pt(II) complex usually has high thermal stability and the emissive excited states show a relatively slow non-radiative decay rate.

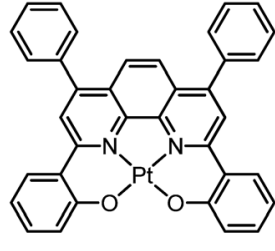

14

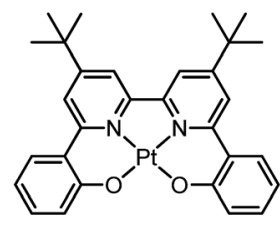

15
In 2003, Che and co-workers reported the first series of phosphorescent $\mathrm{Pt}(\mathrm{II})$ complexes supported by tetradentate dianionic bis(phenoxy)diimine $\left(\mathrm{N}_{2} \mathrm{O}_{2}\right)$ ligands (14 and 15) that have fused 6,5,6-membered rings. ${ }^{70}$ The $\mathrm{Pt}(\mathrm{II})$ ions in the crystal structures of both 14 and 15 adopt a planar coordination geometry and the two $\mathrm{Pt}\left(\mathrm{N}_{2} \mathrm{O}_{2}\right)$ frameworks are highly planar (Fig. 4). Complexes 14 and 15 are stable up to 440 and $530{ }^{\circ} \mathrm{C}$, respectively, in $\mathrm{N}_{2}$. Notably, they also show very high thermal stability in air with significant weight loss at temperatures 
Table 2 Physical data of the Pt(II) complexes supported by a tetradentate ligand

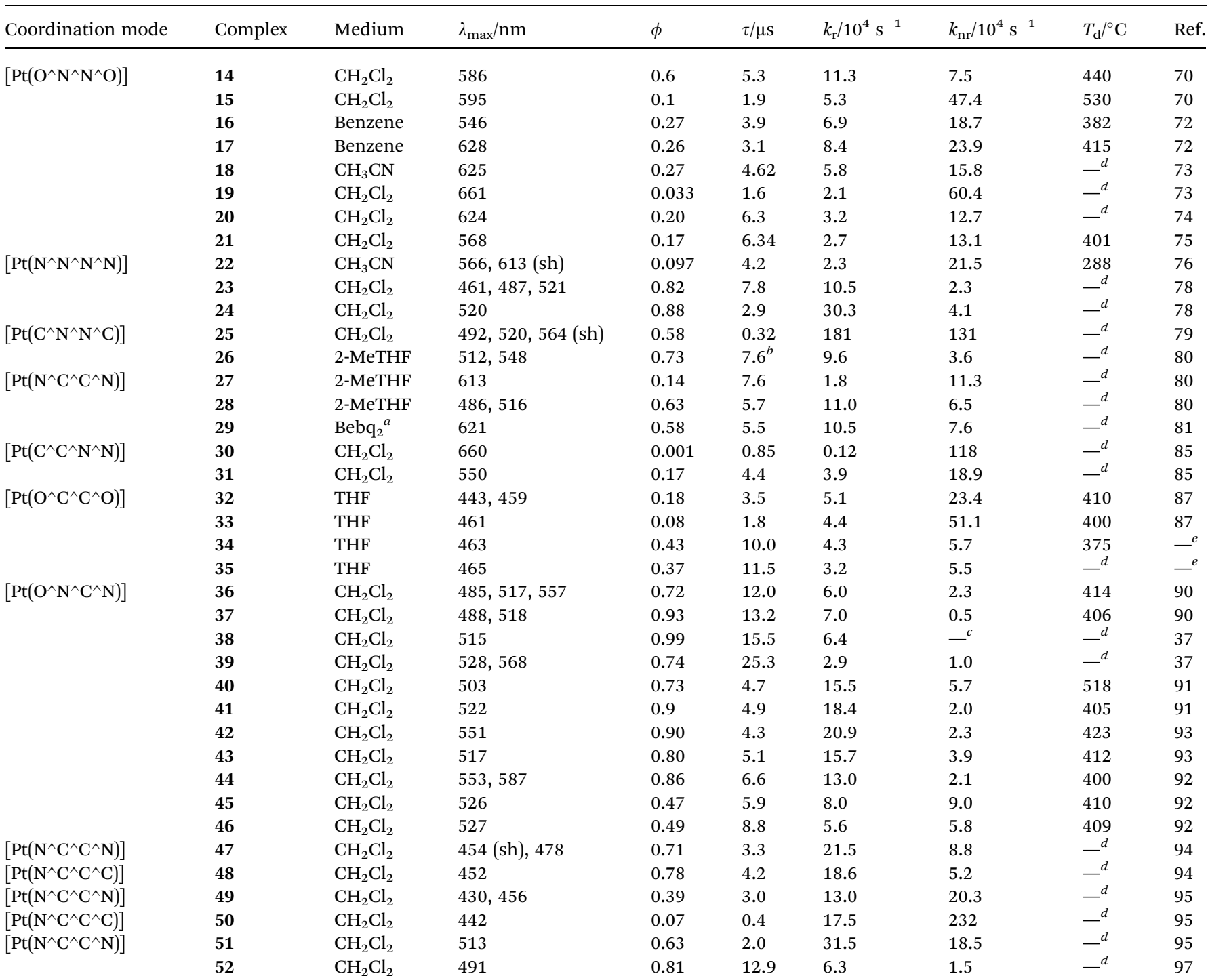

${ }^{a} 6 \mathrm{wt} \%$ doped into a thin film of Bebq ${ }^{b}$ The lifetime $\tau_{0}$ at infinite dilution determined from the linear variation of the observed emission decay rate constant, $k_{\mathrm{obs}}$, as a function of the concentration of the complex. ${ }^{c}$ Value too low to be reported. ${ }^{d}$ Value not available from the literature. ${ }^{e}$ The work that has not been reported.

above approximately $380{ }^{\circ} \mathrm{C}$. Complexes $\mathbf{1 4}$ and 15 display structureless emissions in $\mathrm{CH}_{2} \mathrm{Cl}_{2}$ at room temperature with $\lambda_{\max }=586 \mathrm{~nm}(\phi=0.6 ; \tau=5.3 \mu \mathrm{s})$ and $595 \mathrm{~nm}(\phi=0.1 ; \tau=1.9$ $\mu \mathrm{s})$, respectively. Their potentials as phosphorescent OLED emitters were examined. The maximum brightness (9330 cd $\mathrm{cm}^{-2}$ ) and power efficiency $\left(1.44 \mathrm{~lm} \mathrm{~W}^{-1}\right)$ were recorded for a device using 15 as the dopant. Despite the much higher emission quantum yield of 14 in $\mathrm{CH}_{2} \mathrm{Cl}_{2}$, the device doped with 14 exhibited a low performance that was ascribed to intermolecular quenching (including self-quenching). In contrast, the bulky tert-butyl groups in $\mathbf{1 5}$ are believed to reduce the intermolecular interactions.

In 2004, Che and co-workers reported another tetradentate $\mathrm{N}_{2} \mathrm{O}_{2}$ ligand system, i.e., Schiff base, that can be used for the preparation of phosphorescent Pt(II) emitters. ${ }^{71}$ Detailed photophysical studies of a series of Pt(II) Schiff base complexes were later presented in $2010 .^{72}$ These types of complex are attractive

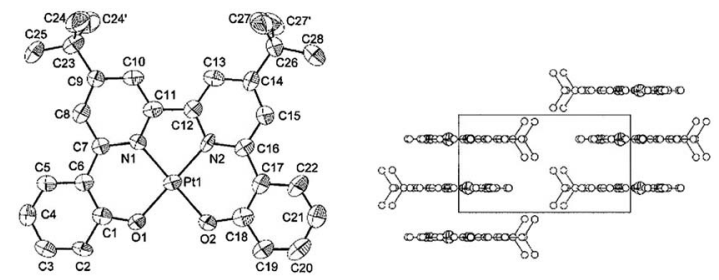

Fig. 4 Perspective view (50\% thermal probability) (left) and packing arrangement along the $a b$ plane (right) of 15 (adapted with permission from ref. 70. Copyright 2003, Wiley-VCH Verlag GmbH \& Co. KGaA). 
in the context of practical applications because of the straightforward preparation of the Schiff base ligands and the simplicity of scaling up for mass production. It is also wellknown that Schiff bases readily form stable transition metal complexes. Not surprisingly, all the Pt(II) Schiff base complexes are stable in the solid state, and no decomposition or ligand dissociation was observed in EtOH, 2-propanol, DMSO, or $\mathrm{CH}_{3} \mathrm{CN}$ under ambient conditions for one month. The $\mathrm{Pt}$ (II) Schiff base complexes display excellent thermal stability with $T_{\mathrm{d}}$ of up to $495{ }^{\circ} \mathrm{C}$ in $\mathrm{N}_{2} \cdot{ }^{72}$ Complex 16 shows an emission with $\lambda_{\max }$ $=546 \mathrm{~nm}$ in benzene. This complex exhibits the highest reported emission quantum yield $(\phi=0.27)$ among this class of Pt(II) emitters. Structural diversity of the Schiff base ligand allows facile tailoring of both the physical and photophysical properties of this class of complexes. Replacing the ethylene linker with a phenyl ring resulted in a red-shifted emission as in the case of 17 ( $\lambda_{\max }=628 \mathrm{~nm}$ and $\phi=0.26$ in benzene). Zerofield splitting (ZFS) can be used to estimate the extent of MLCT perturbation and SOC efficiency of the emitting triplet state as well as to assess the suitability of an emitter for OLED fabrication. ${ }^{1,2}$ The value of ZFS of selected complexes was determined by measuring their temperature-dependent lifetimes in the range of 1.5-130 K. As shown in Fig. 5, the total ZFS for 16 was estimated to be $20 \mathrm{~cm}^{-1}$, belonging to the intermediate range in a library of triplet emitters examined by Yersin and coworkers. ${ }^{72}$ The emitting triplet state was assigned to have ILCT character with significant MLCT perturbation. DFT/TDDFT studies also supported this assignment. Che and co-workers have extended the theoretical studies to the substituent effects on the luminescence efficiency of the $\mathrm{Pt}(\mathrm{II})$ Schiff base complexes. ${ }^{73}$ Replacing the ethylene bridge (16) of the Schiff base ligand with a $\pi$-conjugated phenylene bridge (17) not only widens the ${ }^{3} \mathrm{MLCT}-{ }^{3} \mathrm{~d}-\mathrm{d}$ energy gap due to a lowered ligand $\pi^{*}$ orbital (relative to the $\mathrm{d}_{x^{2}-y^{2}}$ orbital) in 17 (Fig. 6), but also results in a smaller Huang-Rhys factor $\left(S_{\mathrm{M}}=1.05\right.$ and 0.89 for 16 and 17 respectively). As such, though the emission energy of $\mathbf{1 7}$ is smaller than that of $\mathbf{1 6}$ and the former should have a faster non-radiative decay rate than the latter based on the energy gap
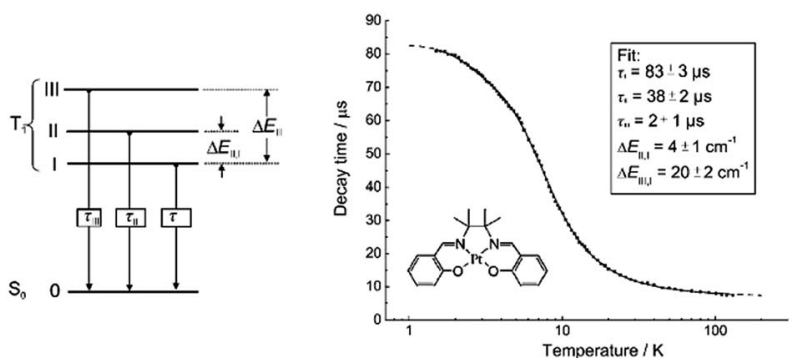

Fig. 5 Schematic energy-state diagram for the substates of the emitting $T_{1}$ state of a transition metal complex (left). Plot of emission decay times of 16 in THF $\left(\sim 10^{-5} \mathrm{M}\right)$ versus temperature and the fit to the equation describing the temperature dependence of the measured decay time in a model of three substates (right) (adapted with permission from ref. 72. Copyright 2010, Wiley-VCH Verlag GmbH \& Co. KGaA). law, both complexes have similar $k_{\mathrm{nr}}$ values in $\mathrm{CH}_{3} \mathrm{CN}$ at room temperature $\left(k_{\mathrm{nr}}=2.31 \times 10^{5} \mathrm{~s}^{-1}\right.$ for 16 and $2.24 \times 10^{5} \mathrm{~s}^{-1}$ for $17)^{72}$ due to the smaller structural distortion in 17. It was also demonstrated in the same work that the nature of the substituents (17-19) can modify the SOC and frequency shifts of the low-frequency modes between the $T_{1}$ and $S_{0}$ states. Inclusion of both factors in addition to the structural distortion allowed quantitative computation of the phosphorescence efficiency. An OLED doped with 16 at an optimized doping concentration of $4.0 \mathrm{wt} \%$ exhibited a maximum EQE, current efficiency, power efficiency, and brightness of $11 \%, 31 \mathrm{~cd} \mathrm{~A}^{-1}, 14 \mathrm{~lm} \mathrm{~W}^{-1}$, and $23000 \mathrm{~cd} \mathrm{~m}^{-2}$, respectively. ${ }^{71}$ Moreover, this device gave stable EL spectra over a wide range of operating voltages from 3 to 16 V. Using the same device configuration as that for 16 , a stable red-OLED using 17 as the dopant was achieved with a maximum EQE and power efficiency of $9.4 \%$ and $4.91 \mathrm{~lm} \mathrm{~W}^{-1}$, respectively. Notably, this device showed a lifetime of more than $20000 \mathrm{~h}$ at $100 \mathrm{~cd} \mathrm{~m}^{-2}$ and the performance was further improved to an impressive $77000 \mathrm{~h}$ at $500 \mathrm{~cd} \mathrm{~m}^{-2}$ by modifying the device configuration. ${ }^{72}$ However, due to the severe self-quenching effect $\left(k_{\mathrm{q}}=6.9 \times 10^{8} \mathrm{M}^{-1} \mathrm{~s}^{-1}\right)$, the optimal device can only be fabricated with a low doping level of 17 ( $<1.5 \mathrm{wt} \%)$. Recently, Che and co-workers prepared a series of derivatives of 17 bearing bulky groups, an example of which is $\mathbf{2 0 .}{ }^{\mathbf{7 4}}$ Complex 20, having norbornene moieties in the ligand scaffold, displays an emission quantum yield of 0.20 with $\lambda_{\max }=624 \mathrm{~nm}$ in $\mathrm{CH}_{2} \mathrm{Cl}_{2}$ and a significantly reduced emission self-quenching rate constant $\left(k_{\mathrm{q}}\right)$ of $1 \times 10^{7} \mathrm{M}^{-1} \mathrm{~s}^{-1}$. As a result, an efficient red OLED could be fabricated at a higher doping concentration of 4 $\mathrm{wt} \%$ and displayed a delayed efficiency roll-off. Wong et al. also reported an asymmetric Pt(II) Schiff base complex 21 with bulky tert-butyl and triphenylamino groups introduced at different sites to prevent aggregation or excimer formation. ${ }^{75}$ Using 21 as the emitter, an efficient yellow OLED $\left(\lambda_{\max }=564 \mathrm{~nm}\right)$ was fabricated at a high doping concentration (8.0 wt\% in TCTA). The EQE, current efficiency, power efficiency, and maximum brightness were $8.3 \%, 23 \mathrm{~cd} \mathrm{~A}^{-1}, 17 \mathrm{~lm} \mathrm{~W}^{-1}$, and $11106 \mathrm{~cd} \mathrm{~m}^{-2}$, respectively. 


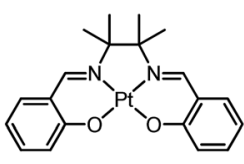

16

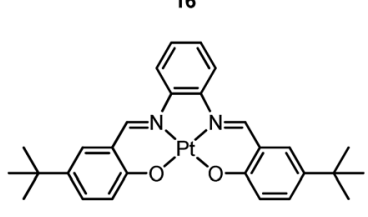

18

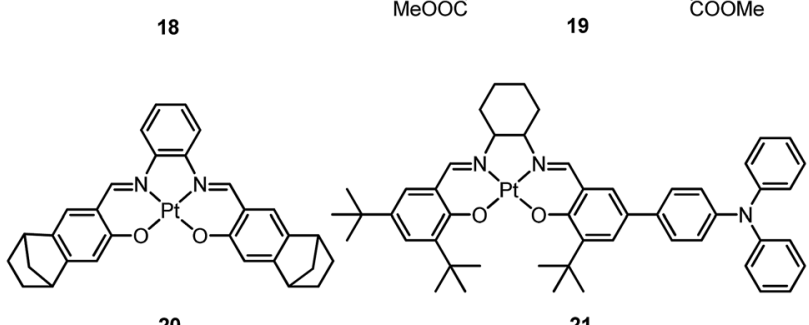

20

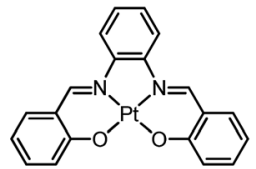

17

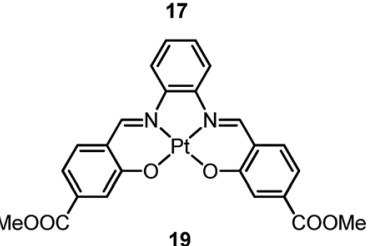

Che and co-workers previously developed a class of phosphorescent $\mathrm{Pt}(\mathrm{II})$ complexes supported by tetradentate bis (pyrrole)-diimine $\left(\mathrm{N}_{4}\right)$ ligands. ${ }^{76}$ Complex 22 displays a yellow emission in dilute $\mathrm{CH}_{3} \mathrm{CN}$ (concentration $\sim 1 \times 10^{-6} \mathrm{M}$ ) with an emission quantum yield and lifetime of 0.097 and $4.2 \mu \mathrm{s}$, respectively. Interestingly, at elevated concentrations in either solution or CBP (CBP $=4,4$ '-bis( $N$-carbazolyl)-1,1'-biphenyl) film, 22 shows a red-shifted emission which has been attributed to the high propensity of $\mathbf{2 2}$ for excimer or oligomer formation. Thus, an OLED doped with 22 at $6.0 \mathrm{wt} \%$ afforded red electroluminescence with a peak maximum at $620 \mathrm{~nm}$ and CIE coordinates of $(0.62,0.38)$. The maximum EQE, current efficiency, power efficiency, and brightness for this device were $6.5 \%, 9.0$ cd $\mathrm{A}^{-1}, 4.0 \mathrm{~lm} \mathrm{~W}^{-1}$, and $11100 \mathrm{~cd} \mathrm{~m}^{-2}$, respectively. High efficiencies were maintained even at a high brightness of 5000 $\mathrm{cd} \mathrm{m}^{-2}\left(5.2 \%, 7.7 \mathrm{~cd} \mathrm{~A}^{-1}\right.$, and $\left.2.4 \mathrm{~lm} \mathrm{~W}^{-1}\right)$. This work represents a proof-of-concept that excimer formation of $\mathrm{Pt}$ (II) complexes can be used to achieve efficient low-energy emission. Indeed, NIR OLEDs based on emission from excimeric and aggregate species have been demonstrated by Williams on pincer-type Pt(II) emitters. ${ }^{54,77}$ However, 22 exhibits a relatively low $T_{\mathrm{d}}$ of 288 ${ }^{\circ} \mathrm{C}$ in $\mathrm{N}_{2}$. This is attributed to the significant strain chelate present in 22 as this complex has a fused 5,5,5-membered metallacycle, without the optimal 6-membered rings. Very recently, Chi and co-workers reported a new type of highly emissive Pt(II) complex supported by a tetradentate ligand with four $\mathrm{N}$ donor atoms. ${ }^{78}$ Complex 23 exhibits blue emission $\left(\lambda_{\max }\right.$ $=461 \mathrm{~nm}, \phi=0.82)$ in $\mathrm{CH}_{2} \mathrm{Cl}_{2}$. This emission has been attributed to a ligand-centred $\pi-\pi^{*}$ transition. Complex 24, having an acridine moiety, possesses a dominant chargetransfer character in its lowest triplet excited state. As a result, this complex displays significant solvatochromism. Upon switching the solvent from cyclohexane to $\mathrm{CH}_{2} \mathrm{Cl}_{2}$, the emission quantum yield and lifetime change from 0.13 and $20.1 \mu$ s to 0.88 and $2.9 \mu \mathrm{s}$, respectively. The increased $k_{\mathrm{r}}$ is due to the variation of emission character from $\pi-\pi^{*} / \mathrm{MLCT}$ to ILCT/
MLCT. Both 23 and 24 have been used for sky-blue OLED fabrications. The CIE coordinates, peak EQE, and maximum brightness were $(0.190,0.342) /(0.194,0.391), 12.3 \% / 15.3 \%$, $1924 / 4121 \mathrm{~cd} \mathrm{~m}^{-2}$ for 23/24 based OLEDs.

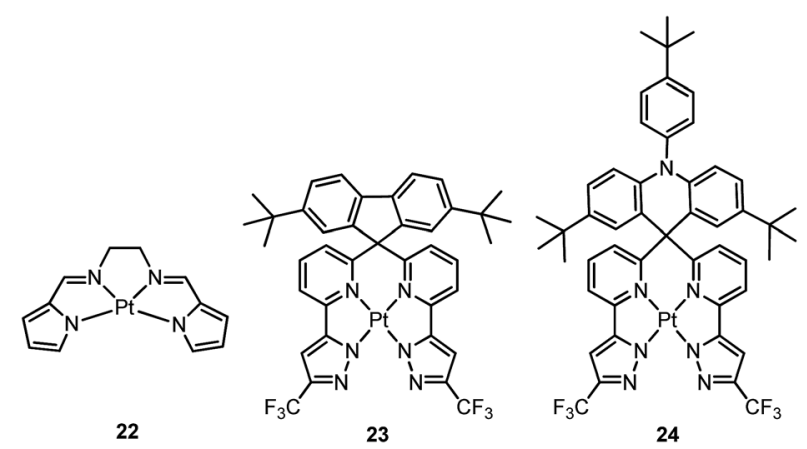

Recently, there has been considerable interest in tetradentate ligand systems containing deprotonated C-atoms and/ or NHCs. These ligand systems have been shown to afford superior Pt(II) emitters in terms of both emission efficiency and/ or robustness. In 2009, Weck et al. developed complexes containing doubly cyclometalated tetradentate ligands $\left(\mathrm{C}^{\wedge} \mathrm{N}^{\wedge} \mathrm{N}^{\wedge} \mathrm{C}\right) .{ }^{79}$ Complex 25 shows vibronic-structured phosphorescence in $\mathrm{CH}_{2} \mathrm{Cl}_{2}$ with a quantum yield of $0.58\left(\lambda_{\max }=492\right.$ $\mathrm{nm})$. In 2010, Huo and co-workers reported a related system in which the cyclometalated $\mathrm{C}^{\wedge} \mathrm{N}$ motifs are bridged by an amino group as in the case of $26{ }^{80}$ Complex 26 exhibits an intense green $\left(\lambda_{\max }=512 \mathrm{~nm}\right)$ vibronic structured emission in 2-MeTHF with a quantum yield of 0.74 . Upon incorporation of 26 at $4 \mathrm{wt} \%$ in a mixed host into an OLED, an excellent device performance with a maximum EQE of $14.7 \%$ was observed. Crystal structures reveal that the $\mathrm{Pt}-\mathrm{C}$ distances of 2.00-2.01 $\AA$ for 25 and 26 are close to those of $\sim 2.00 \AA$ for $\mathrm{Pt}(\mathrm{ppy})_{2}$ (ppy = deprotonated 2phenylpyridine) while the Pt-N bond lengths of 2.05-2.08 A are shorter than those of $\mathrm{Pt}(\mathrm{ppy})_{2}(\sim 2.13 \AA)$. In the same work, Huo also reported the photophysical properties of the $\mathrm{Pt}(\mathrm{II})-$ $\mathrm{N}^{\wedge} \mathrm{C}^{\wedge} \mathrm{C}^{\wedge} \mathrm{N}$ complexes (e.g., 27 and 28 ) that are isomeric derivatives of the $\mathrm{Pt}(\mathrm{II})-\mathrm{C}^{\wedge} \mathrm{N}^{\wedge} \mathrm{N}^{\wedge} \mathrm{C}$ ones. ${ }^{80}$ Similar to the findings for 25 and 26, the formation of a metallacycle results in shorter $\mathrm{Pt}-\mathrm{C}$ bond distances $(\sim 1.96 \AA)$ for 27 , when compared with those of cis-Pt(ppy $)_{2}(\sim 1.99 \AA)$. Complex 27 emits red light in 2-MeTHF with $\lambda_{\max }$ at $613 \mathrm{~nm}(\phi=0.14)$. Replacing the pyridyl ring in 27 with the less electron-accepting pyrazolyl ring resulted in a hypsochromic shift of the emission and enhanced emission efficiency, as in the case of $28\left(\lambda_{\max }=486 \mathrm{~nm}, \phi=0.63\right)$. Compared to 27 , the enhancement of $\phi$ for 28 is attributed mainly to an increased $k_{\mathrm{r}}\left(k_{\mathrm{r}}=1.1 \times 10^{5} \mathrm{~s}^{-1}\right.$ for $28 v s .1 .8 \times 10^{4}$ $\mathrm{s}^{-1}$ for 27). However, DFT calculations show a comparable metal parentage in the HOMOs of $\mathbf{2 7}$ and $\mathbf{2 8}$ and, therefore, the metal character of the frontier orbital is not sufficient to account for such a large variation in the $k_{\mathrm{r}}$ value. In fact, the factors affecting the radiative decay rate constant are complex. It is necessary to take into account, in addition to spin-orbit coupling (SOC) matrix elements, the singlet-triplet energy gap and the oscillator strength of the transition from $S_{0}$ to the singlet excited 
state from which the triplet excited state borrows intensity. ${ }^{31}$ Fukagawa and co-workers later modified 27 by attaching two tert-butyl groups to the $N$-pendant phenyl ring to give 29, which emits red light $\left(\lambda_{\max }=621 \mathrm{~nm}\right)$ with a quantum yield of $0.58 \mathrm{in}$ a bis(benzo[ $h]$ quinolin-10-olato- $k N, k O$ )beryllium(II) (Bebq $\left.{ }_{2}\right)$ film. ${ }^{81}$ The optimized OLED doped with 29 showed good colour saturation with CIE coordinates of $(0.66,0.34)$, low driving voltage, high efficiency, and high operational stability. The maximum EQE of over $19 \%$ and maximum power efficiency of $30 \mathrm{~lm} \mathrm{~W}^{-1}$ were comparable to the highest values previously reported for red OLEDs using Ir(III) complexes. ${ }^{\mathbf{8 2 - 8 4}}$ The estimated half-life for the optimized OLED was about $10000 \mathrm{~h}$ with an initial brightness of $1000 \mathrm{~cd} \mathrm{~m}^{-2}$.

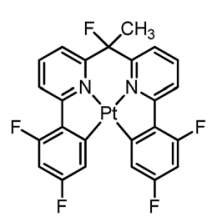

25

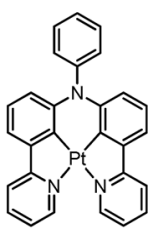

27

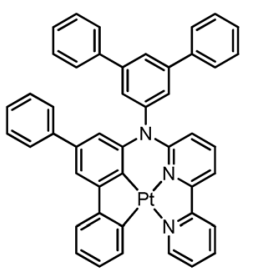

30

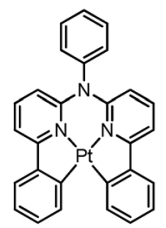

26

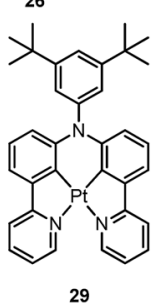

28

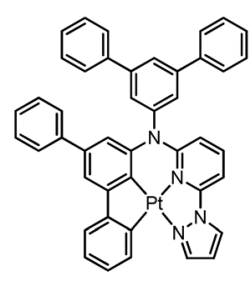

31
Huo and co-workers later reported the synthesis of $\mathrm{Pt}(\mathrm{II})-$ $\mathrm{C}^{\wedge} \mathrm{C}^{\wedge} \mathrm{N}^{\wedge} \mathrm{N}$ complexes 30 and $31 .{ }^{85}$ Complex 30, a closely-related analogue of 25 and 27 , is only weakly emissive $(\phi=0.001)$ in the deep red region with a $\lambda_{\max }$ of $660 \mathrm{~nm}$. Replacement of the pyridyl ring of 30 with a pyrazolyl ring results in bright yellow phosphorescence at $\lambda_{\max }=550 \mathrm{~nm}(\phi=0.17)$. The Huang-Rhys factors for $\mathbf{3 0}$ and $\mathbf{3 1}$ were estimated to be 0.42 and 0.37 respectively, comparable to those found in $\mathrm{Pt}(\mathrm{II})-\mathrm{C}^{\wedge} \mathrm{N}^{\wedge} \mathrm{N}^{\wedge} \mathrm{C}$ and $\mathrm{Pt}(\mathrm{II})-\mathrm{N}^{\wedge} \mathrm{C}^{\wedge} \mathrm{C}^{\wedge} \mathrm{N}$ complexes, indicating that these complexes should have similar structural distortion between the emitting triplet excited state and ground state. The much faster nonradiative decay rate of $30\left(k_{\mathrm{nr}}=1.2 \times 10^{6} \mathrm{~s}^{-1}\right)$ is therefore likely to be associated with its lower energy emission, a consequence of the "energy-gap law". ${ }^{86}$ On the other hand, although DFT calculations show that the triplet excited states of $\mathbf{3 0}$ and $\mathbf{3 1}$ are ILCT mixed with MLCT, the distinctly larger $k_{\mathrm{r}}$ of $3.9 \times 10^{4} \mathrm{~s}^{-1}$ for 31 over $30\left(k_{\mathrm{r}}=1.2 \times 10^{3} \mathrm{~s}^{-1}\right)$ reflects the significant dependence of $k_{\mathrm{r}}$ on subtle ligand modification, again as for that observed for 28 over 27.

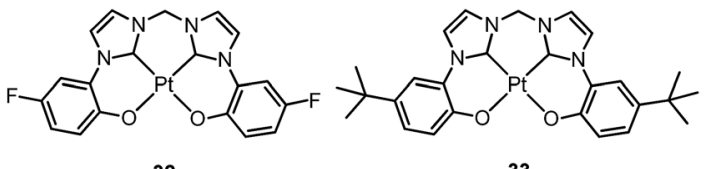

32

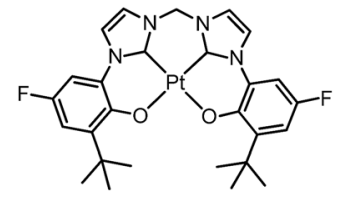

34

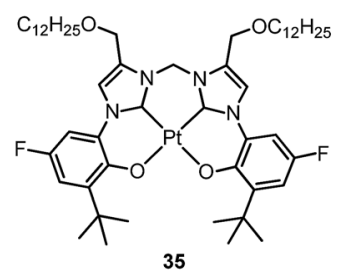

35
Che's and Strassner's groups independently reported tetradentate $\mathrm{Pt}(\mathrm{II})$ complexes containing dianionic bis(phenolateNHC) ligands. ${ }^{87,88}$ The fused 6,6,6-membered metallacycle allows an ideal coordination geometry around the Pt atom with all bite angles being $90 \pm 2{ }^{\circ} .{ }^{87}$ As expected, the optimum chelate ring size together with the strong $\sigma$-donating $\mathrm{C}$ and $\mathrm{O}$ donor atoms render these complexes with good thermal stability with a $T_{\mathrm{d}}$ of up to $\sim 410{ }^{\circ} \mathrm{C}$ in $\mathrm{N}_{2}$. In poly(methyl methacrylate) (PMMA), both 32 and 33 exhibit deep blue phosphorescence $\left(\lambda_{\max } \sim 450 \mathrm{~nm}\right)$ with emission efficiencies of $c a$. 0.3. This is the first report on deep blue emission from Pt(II) complexes supported by tetradentate ligands. ${ }^{87}$ On the basis of photophysical studies and DFT calculations, the emitting states have been assigned to have mainly ILCT character with MLCT perturbation, similar to the Pt(II) Schiff base complexes. The femtosecond spectroscopic technique has proven useful in providing valuable information to understand the ultrafast excited state dynamics. As depicted in Fig. 7, upon photoexcitation, the $\mathrm{S}_{1}$ state of 33 undergoes an ultrafast ISC process with a fluorescence lifetime of $0.19 \mathrm{ps}$, revealing that the involved MLCT character is sufficient for promoting the ISC process. ${ }^{89}$ Recently, Che and co-workers prepared two new complexes 34 and 35, containing para-F and ortho- ${ }^{t} \mathrm{Bu}$ groups (Scheme $\mathrm{S} 1$ in $\mathrm{ESI} \dagger$ ). These complexes show improved emission quantum yields of 0.43 and 0.37 in THF, respectively (Fig. S3, ESI $\dagger$ ). The $k_{\mathrm{r}}$ values (4.4-5.1 $\left.\times 10^{4} \mathrm{~s}^{-1}\right)$ of 32-35 are comparable and the emission
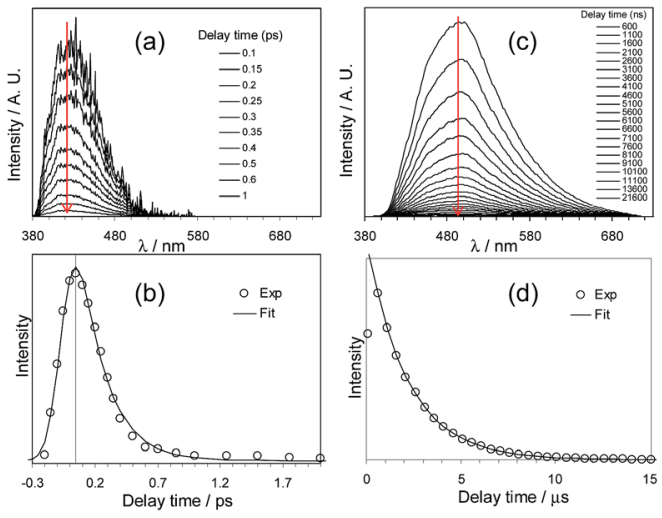

Fig. 7 fs-TRF and ns-TRE spectra (a and c) and decay profiles ( $b$ and d) recorded at the various denoted delay times after $355 \mathrm{~nm}$ excitation of 33 in DMF (reproduced from ref. 89 with permission from the Royal Society of Chemistry). 
variations mainly arising from their differences in non-radiative decay rates (Table 2). It is rational to assume that the ligandfield strength, and thus d-d energy level, is not much affected by the peripheral substitutions on the ligand in the present system. Given their close emission energies (443-465 $\mathrm{nm}$ ), the non-radiative relaxations for 32-35 via thermal population of the ${ }^{3} \mathrm{~d}-\mathrm{d}$ states are envisaged to be comparably marginal. For the same reason, the extent of the energy-gap law contribution to the non-radiative decay should be similar. Thus, excited state $\left(\mathrm{T}_{1}\right)$ geometry distortions with respect to the ground state are conceived to be the cause for such differences in the non-radiative decay rate for 32-35. For complexes having the same excited state nature $\left({ }^{3} \mathrm{LLCT} /{ }^{3} \mathrm{MLCT}\right)$, an indicator of the geometry distortion from $S_{0}$ to $T_{1}$ is the absorption-emission Stokes shift. A comparison of the absorption and emission spectra of 32-34 in DMF is shown in Fig. S4 (ESI $\dagger$ ). The para-F and ortho- ${ }^{t} \mathrm{Bu}$ substituents are effective in reducing excited state structural distortions, leading to decreased absorption-emission Stokes shifts from $\mathbf{3 3}$ to $\mathbf{3 2}$ and $\mathbf{3 4}$.

The device doped with 33 at $4 \mathrm{wt} \%$ in the host of 9-(4-tertbutylphenyl)-3,6-bis(triphenylsilyl)-9H-carbazole (CzSi) afforded blue phosphorescence with CIE coordinates of $(0.19,0.21) .^{89}$ The maximum EQE, current efficiency, power efficiency, and brightness were $15 \%, 23.8 \mathrm{~cd} \mathrm{~A}^{-1}, 16.6 \mathrm{~lm} \mathrm{~W}^{-1}$ and $9500 \mathrm{~cd}$ $\mathrm{m}^{-2}$, respectively. ${ }^{89}$ The EL spectrum was stable in the operating voltage of 6-11 V. In combination with a co-deposited yellow phosphorescent Pt(II) complex, a white light-emitting electrophosphorescent device was obtained with CIE coordinates, maximum brightness, and current efficiency of $(0.32,0.42)$,

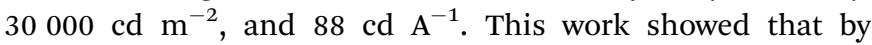
including an NHC motif in the tetradentate ligand scaffold, efficient deep blue phosphorescent $\mathrm{Pt}(\mathrm{II})$ materials can be generated.

Based on the comparisons between the above-mentioned tetradentate $\mathrm{Pt}$ (II) complexes (Table 2), it is conceived that coordination geometry with short $\mathrm{Pt}-\mathrm{C}$ bonds and the presence of a fused 6-membered ring may be advantageous in the design of robust, strongly luminescent Pt(II) emitters. Recently Che and co-workers devised an asymmetric $\mathrm{O}^{\wedge} \mathrm{N}^{\wedge} \mathrm{C}^{\wedge} \mathrm{N}$ ligand system that features a metallacycle having fused 6,5,5-membered rings (selected examples 36-39)..$^{37,90}$ The decomposition temperature of this series of complexes is higher than $400{ }^{\circ} \mathrm{C}$ (Table 2). All complexes exhibit vibronic-structured emission in $\mathrm{CH}_{2} \mathrm{Cl}_{2}$ and the emitting state has been assigned as metal-perturbed ${ }^{3} \pi-\pi^{*}$ of the $\mathrm{O}^{\wedge} \mathrm{N}^{\wedge} \mathrm{C}^{\wedge} \mathrm{N}$ ligand. The emission quantum yields of this series of $\mathrm{Pt}-\mathrm{O}^{\wedge} \mathrm{N}^{\wedge} \mathrm{C}^{\wedge} \mathrm{N}$ complexes are higher than 0.65 and the emission energy can be tuned from 485 to $528 \mathrm{~nm}$. Complexes 36-39, bearing rigid fluorenyl-like moieties in their $\mathrm{O}^{\wedge} \mathrm{N}^{\wedge} \mathrm{C}^{\wedge} \mathrm{N}$ frameworks have small $k_{\mathrm{nr}}$ values in the range of $0.06-2.3 \times 10^{4}$ $\mathrm{s}^{-1}$. This is in contrast to the related Pt(II) complexes without the dialkylmethylene bridge, which generally have $k_{\mathrm{nr}}$ values $>2.0 \times 10^{4} \mathrm{~s}^{-1}$ (vide infra). Notably, 38 exhibits an emission efficiency of almost one $(\phi=0.99)$ in solution at room temperature. ${ }^{37}$ Attachment of bulky $N$-carbazolyl groups to the $\mathrm{O}^{\wedge} \mathrm{N}^{\wedge} \mathrm{C}^{\wedge} \mathrm{N}$ ligand scaffold to give 38 results in a significant suppression of intermolecular interactions leading to the fabrication of high-efficiency $(\mathrm{EQE}=15.6 \%)$ monochromic polymer light-emitting diodes (PLEDs). ${ }^{37}$

Complexes 40 and 41 are related analogues of 36-39, bearing $\mathrm{O}^{\wedge} \mathrm{N}^{\wedge} \mathrm{C}^{\wedge} \mathrm{N}$ ligand scaffolds but without a dialkylmethylene bridge. ${ }^{91}$ The former complexes are also strongly emissive $(\phi=$ 0.73-0.90 in $\left.\mathrm{CH}_{2} \mathrm{Cl}_{2}\right)$ and thermally stable $\left(T_{\mathrm{d}}>400{ }^{\circ} \mathrm{C}\right.$ ) (Table 2 ). It is worth noting that the $k_{\mathrm{r}}$ and $k_{\mathrm{nr}}$ values for $\mathbf{4 0}$ and $\mathbf{4 1}$ are higher than those of 36-39. Consequently, the lifetimes of the former are shortened to fewer than $5 \mu$ s while high emission efficiencies are maintained. The bulky norbornene group in $\mathbf{4 1}$ was observed to suppress intermolecular interactions, thus disfavouring excimer formation and self-quenching in solution. The high emission efficiency, good thermal stability and ineffective self-quenching property altogether rendered highly phosphorescent OLEDs at a high doping concentration of $\mathbf{4 1}$. The device doped with 13 wt\% of $\mathbf{4 1}$ in 1,3-bis( $N$-carbazolyl) benzene (mCP) exhibited green phosphorescence with a maximum EQE and peak current efficiency of $18.2 \%$ and 66.7 $\mathrm{cd} \mathrm{A}^{-1}$, respectively. These values are among the highest values for green OLEDs using Pt(II) emitters. It should be noted that this device showed a very low efficiency roll-off of only $2.4 \%$ at $1000 \mathrm{~cd} \mathrm{~m}^{-2}\left(65.1 \mathrm{~cd} \mathrm{~A}^{-1}\right)$.

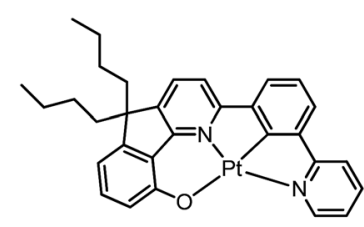

36

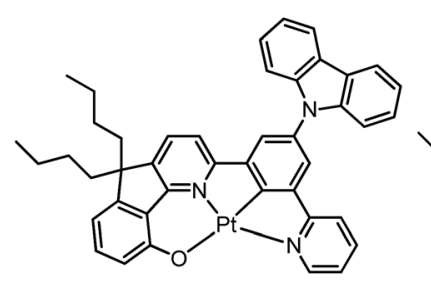

38

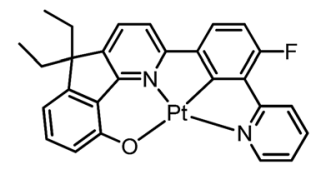

37

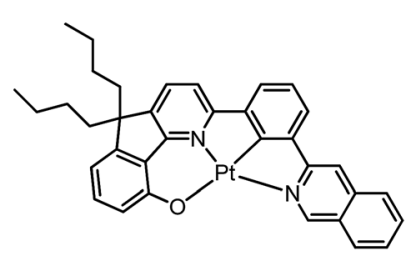

39
Che has further expanded this $\mathrm{O}^{\wedge} \mathrm{N}^{\wedge} \mathrm{C}^{\wedge} \mathrm{N}$ ligand system by inclusion of an additional bridging atom to form fused 6,5,6membered rings (e.g. 42-46). ${ }^{92,93}$ Complexes 42-46 exhibit strong emission ( $\phi=0.47-0.90$ in $\left.\mathrm{CH}_{2} \mathrm{Cl}_{2}\right)$ in the yellow-togreen spectral region (Table 2). Contrary to $\mathbf{4 4}$ which has a sterically unencumbered ligand scaffold, 42 and 43 have a bulky orthogonal bridging tertiary amine unit and a biphenyl group with a spiro-linkage respectively; these structural motifs efficiently suppress intermolecular interactions, which is in agreement with both the X-ray crystal structure of 43 and the optimized geometry of the dimer of 42 and 43 using DFT calculations. ${ }^{93}$ As a result, the emission self-quenching rate constants $\left(k_{\mathrm{q}}\right)$ are as low as $2.0 \times 10^{7}$ and $1.1 \times 10^{7} \mathrm{M}^{-1}$ $\mathrm{s}^{-1}$, respectively. With an optimized device structure, maximum power efficiencies of 118 and $126 \mathrm{~lm} \mathrm{~W}^{-1}$ have been achieved with the respective yellow-emitting 42- and green-emitting 43-based OLEDs. These values are the highest 
among the reported $\mathrm{Pt}(\mathrm{II})$-OLEDs; the maximum EQE were respectively $26.0 \%$ and $27.6 \% .^{93}$ The emission property of $\mathbf{4 4}$ is comparable to that of $\mathbf{4 2}$, revealing that the emitting state is localized on the $\mathrm{O}^{\wedge} \mathrm{N}^{\wedge} \mathrm{C}^{\wedge} \mathrm{N}$ motif without significant involvement of the tertiary amine linkage. ${ }^{92}$ The monochromic OLED using 44 as the dopant exhibited a power efficiency of $52.1 \mathrm{~lm}$ $\mathrm{W}^{-1}$ which was comparable to those of the best Ir(III)-based yellow OLEDs. In a modified device structure comprising a composite blue host and 44, a WOLED was obtained with an estimated power efficiency of $61 \mathrm{~lm} \mathrm{~W}{ }^{-1}$. In degassed $\mathrm{CH}_{2} \mathrm{Cl}_{2}$, complexes 45 and $\mathbf{4 6}$ show moderate emission quantum yields of 0.47 and 0.49 , which are relatively lower than those of $\mathbf{4 2}$ and 44.

$\mathrm{Li}$ and co-workers have developed a series of $\mathrm{Pt}(\mathrm{II})$ complexes containing tetradentate ligands of which the conventional cyclometalated fragment $\mathrm{C}^{\wedge} \mathrm{N}$ is bridged by an $\mathrm{O}$ atom to a chelating $L^{\wedge} L^{\prime}$ ancillary ligand, resulting in a metallacycle having fused 6,6,5-membered rings (e.g. 47-51). ${ }^{94,95}$ Complexes 47 and $\mathbf{4 8}$ having an ancillary pyridyl-carbazole ligand display intense blue phosphorescence in $\mathrm{CH}_{2} \mathrm{Cl}_{2}$ with $\lambda_{\max }(\phi)$ of $478 \mathrm{~nm}(0.71)$ and $452 \mathrm{~nm}(0.78)$, respectively. ${ }^{94}$ Interestingly, the full-width at half-maximum (FWHM) of $\mathbf{4 7}$ decreases from $85 \mathrm{~nm}$ to $20 \mathrm{~nm}$ upon attaching an electrondonating ${ }^{t} \mathrm{Bu}$ group to the 4-position of the pyridyl ring. ${ }^{96}$ Similar spectral narrowing has also been observed for 48. It was conceived that the highly rigid ancillary carbazolyl pyridine motif serves to suppress structural distortion between the triplet emitting state and the ground state, leading to high efficiency emission for this system of Pt(II) emitters. Moreover, ensuring the localization of the $T_{1}$ state on the designed lumophore ligand by this design strategy serves to suppress vibrational progressions of the triplet emitting state, leading to emission spectra with small Huang-Rhys factors. In addition to a bridging oxygen atom, Li and co-workers have developed a related system in which pyrazolyl-carbazole was selected to function as the lumophore ligand, as shown in $\mathbf{5 2 .}{ }^{97}$ This new ligand design imposes further rigidity on the complex because of the conjugated nature of the bridging carbazolyl unit within 52. As a result, a green emission $\left(\lambda_{\max }=491 \mathrm{~nm}\right)$ with improved efficiency $(\phi=0.81)$ and a narrow band (FWHM $=18$ $\mathrm{nm})$ was achieved for 52. High-efficiency blue OLEDs with respective EQE of $25.2 \%$ and $23.7 \%$ were obtained based on $\mathbf{4 7}$ and $48 .{ }^{94}$ Using a ${ }^{t} \mathrm{Bu}$-derivative of $\mathbf{4 8}$ as the dopant, a highly efficient $(\mathrm{EQE}=24.8 \%)$ pure blue OLED with CIE coordinates of $(0.15,0.08)$ was developed ${ }^{96}$ A green OLED based on 52 demonstrated a high maximum EQE of $25.6 \%$ as well as a very small efficiency roll-off $\left(\mathrm{EQE}=25.5 \%\right.$ at $\left.100 \mathrm{~cd} \mathrm{~m}^{-2}\right) .^{97}$ Complexes 49-51, having more flexible frameworks, show less intense emission in solution. ${ }^{95}$ In $\mathrm{CH}_{2} \mathrm{Cl}_{2}$, the emission quantum yields of $\mathbf{4 9}$ and $\mathbf{5 1}$ are 0.39 and 0.63 while that of $\mathbf{5 0}$ becomes significantly low (0.07). In PMMA, 51 emits with an efficiency of almost one in the green spectral region. A green phosphorescent OLED using $\mathbf{5 1}$ as the dopant showed a maximum EQE of $22.3 \%$ which was comparable to that of a $f a c-\operatorname{Ir}(\mathrm{ppy})_{3}$-based device $(\mathrm{EQE}=23.6 \%)$ with the same device structure.
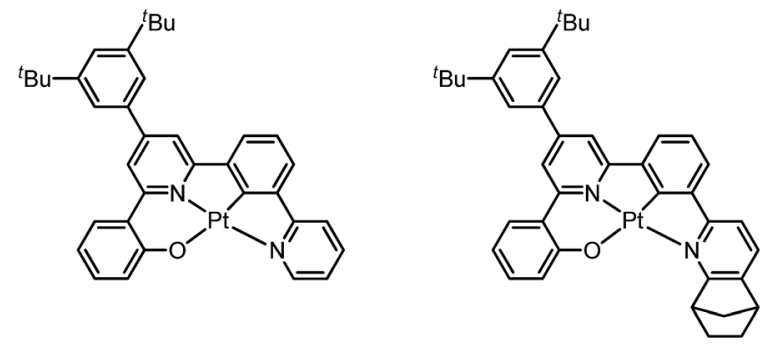

40

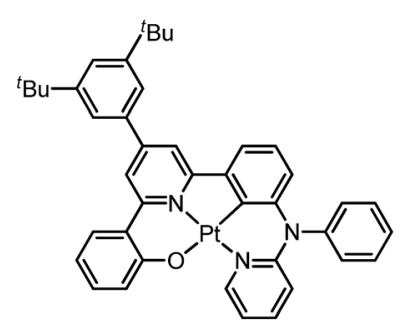

42

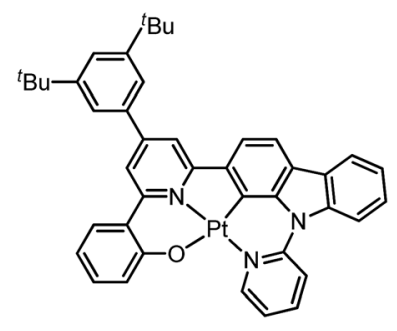

44

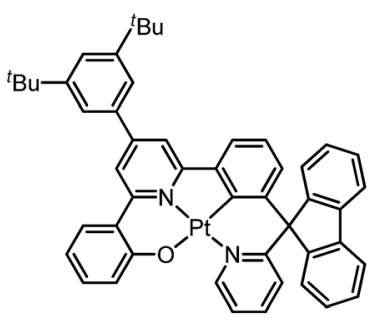

43

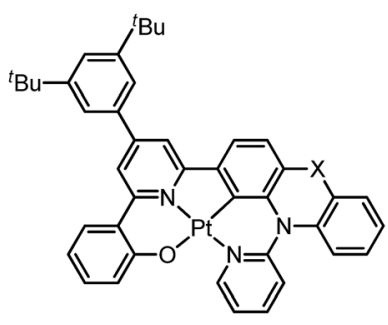

$X=O 45 ; X=S, 46$

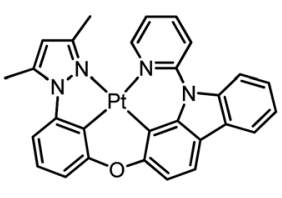

47

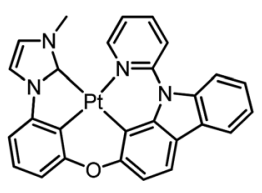

48

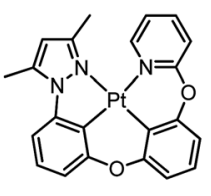

49

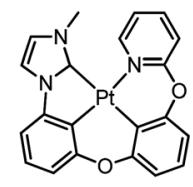

50

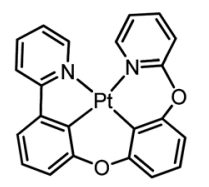

51

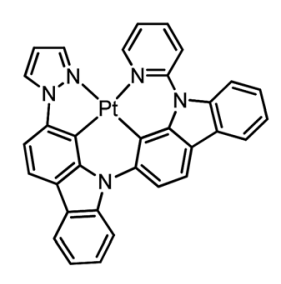

52

\section{Self-assembly of luminescent platinum(॥) complexes with material applications}

Luminescent Pt(II) complexes containing sterically undemanding $\pi$-conjugated ligand(s) are prone to associate with each other, driven by intermolecular Pt $\cdots \mathrm{Pt}$ and/or $\pi-\pi$ interactions (Scheme 3). Miskowski et al. pioneered the spectroscopic studies on Pt(II) complexes of aromatic diimines ${ }^{8}$ and terpyridines ${ }^{98,99}$ revealing 
monomer

aggregate
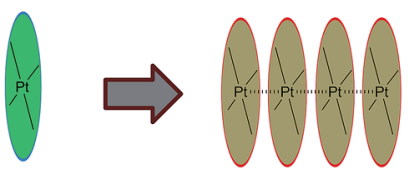

\section{$p_{z}$}

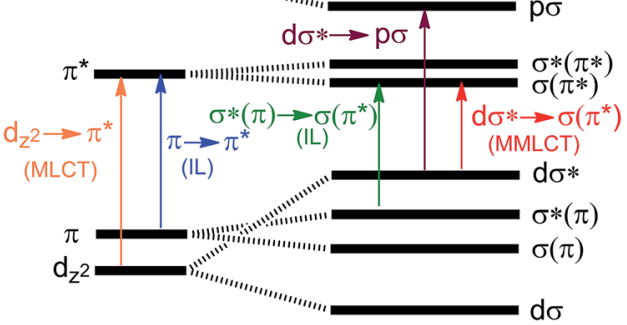

Scheme 3 Proposed molecular orbital diagram illustrating $d^{8}-d^{8}$ and $\pi-\pi$ interactions in $\mathrm{Pt}(\Perp)$ complexes by Miskowski and co-workers in ref. 101.

that the absorption and emission energies in the solid state are significantly red-shifted in the presence of intermolecular Pt $\cdots \mathrm{Pt}$ and/or $\pi-\pi$ interactions. The low energy excited states have been termed metal-metal-to-ligand charge transfer ( $\left.{ }^{3} \mathrm{MMLCT}\right)$ states. Che and co-workers first reported that a dinuclear Pt(trpy) complex with a rigid guanidine bridge displays a moderately intense absorption at $483 \mathrm{~nm}$ and weak phosphorescence at 620 $\mathrm{nm}$ in degassed $\mathrm{CH}_{3} \mathrm{CN}$; both phenomena were attributed to the MMLCT excited states. ${ }^{100}$ According to Miskowski and coworkers, the axial $5 \mathrm{~d}_{z^{2}}$ orbitals of two $\operatorname{Pt}(\mathrm{II})$ ions in close proximity overlap to give bonding $\mathrm{d} \sigma$ and antibonding $\mathrm{d} \sigma^{*}$ orbitals (Scheme 3). ${ }^{101}$ Similarly, the $\pi$ and $\pi^{*}$ orbitals localized on the $\pi$ conjugated ligand can also interact with each other, producing bonding $\sigma(\pi)$ and $\sigma\left(\pi^{*}\right)$ and antibonding $\sigma^{*}(\pi)$ and $\sigma^{*}\left(\pi^{*}\right)$ orbitals. As a consequence, a d $\sigma^{*} \rightarrow \sigma\left(\pi^{*}\right)$ (MMLCT) transition (Scheme 3) occurs with a reduced energy gap, accounting for the red-shifted absorption and emission maxima. Other than MMLCT excited states, $\sigma^{*}(\pi)-\sigma\left(\pi^{*}\right)$ transitions (Scheme 3 ), as a result of intermolecular $\pi-\pi$ interactions, may also lead to electronic excited states of relatively low energy ${ }^{102}$ Importantly, intermolecular Pt $\cdots$ Pt and/or $\pi-\pi$ interactions can occur not only between two ground state molecules but also between an excited state molecule and a ground state one, resulting in lower-energy emissive excimeric ${ }^{3}$ MMLCT or ${ }^{3}\left[\sigma^{*}(\pi)-\sigma\left(\pi^{*}\right)\right]$ (usually simplified as $\left.{ }^{3} \pi-\pi^{*}\right)$ excited states. ${ }^{44}$

The intriguing spectroscopic properties dictated by the unique intermolecular $\mathrm{Pt} \cdots \mathrm{Pt}$ and/or $\pi-\pi$ interactions between two ground state molecules or between an excited state molecule and a ground state one can be harnessed for material applications including: (1) excimeric emission for single-dopant WOLEDs; (2) formation of superstructures with optoelectronic applications.

\subsection{Single-dopant WOLEDs}

In principle, when doped at an appropriate concentration into a host material, the high-energy (in the blue to bluish green region) monomeric and low-energy (in the yellow to red region) excimeric emissions from Pt(II) emitters can be produced simultaneously, giving rise to a white-light emission (Fig. 8). In contrast to WOLEDs that typically comprise three primary colours (i.e. red, green, and blue) or two complementary emission colours (blue and yellow) from multiple phosphorescent emitters, single-dopant WOLEDs offer several advantages. ${ }^{103}$ First, precise control of the relative amount of each dopant for achieving an optimal cascade energy transfer within the emitting layer having multiple dopants is not necessary as only one $\mathrm{Pt}(\mathrm{II})$ dopant is used. Satisfactory white-light emission can be reached by adjusting the concentration of the single $\mathrm{Pt}(\mathrm{II})$ dopant that displays both highly efficient monomeric and excimeric emissions. Second, EL spectral aging due to different dopant aging processes can be excluded as only one molecular light-emitting species is involved, rendering a stable EL spectrum with long-term operation. In the literature, the first excimer-based single-dopant phosphorescent WOLED was demonstrated using $\mathbf{5 3} .^{104}$ This complex was reported to display a blue monomeric and orange excimeric emission when doped into a host matrix. ${ }^{104,105}$ Later, pincer-type $\mathrm{Pt}(\mathrm{II})$ complexes $\mathbf{5 4}$ and 55, containing $\mathrm{N}^{\wedge} \mathrm{C}^{\wedge} \mathrm{N}$ ligands, were examined for this purpose. ${ }^{58,106}$ Complexes 54 and 55 show efficient blue phosphorescence $\left(\lambda_{\max }=453-472 \mathrm{~nm}\right)$ with quantum yields of $0.60-$ 0.80 in dilute $\mathrm{CH}_{2} \mathrm{Cl}_{2}$, which is in stark contrast to $53(\phi=0.02$ in $\left.\mathrm{CH}_{2} \mathrm{Cl}_{2}\right){ }^{42}$ However, for all the complexes 53-55, white EL with a high efficiency and satisfactory CIE as well as CRI were not obtained due to either inefficient monomer emission or inappropriate excimer emission. In 2013, Li and co-workers reported the first high-performance single-dopant WOLED with an EQE $>20 \%$, a satisfactory CIE of $(0.33,0.33)$, and a CRI of 80 using the pincer-type $\mathbf{5 6}$ supported by an NHC-based cyclometalated ligand. ${ }^{107}$ Recently, the EQE of a single-dopant WOLED was boosted to over $25 \%$ by Li's group and Che's group by using 57, 58 or 60 as the emitter. ${ }^{93,108}$ Complex 57 displays efficient blue emission in $\mathrm{CH}_{2} \mathrm{Cl}_{2}$ at $\lambda_{\max }=471 \mathrm{~nm}$ with a quantum yield and lifetime of 0.77 and $3.2 \mu$ s, respectively. ${ }^{108}$ This complex also shows very efficient excimeric emission at elevated concentrations when doped into a host material. As a consequence, the WOLED singly doped with $\mathbf{5 7}$ exhibited a peak EQE of $25.7 \%$. A series of related $\mathrm{Pt}(\mathrm{II})$ emitters with

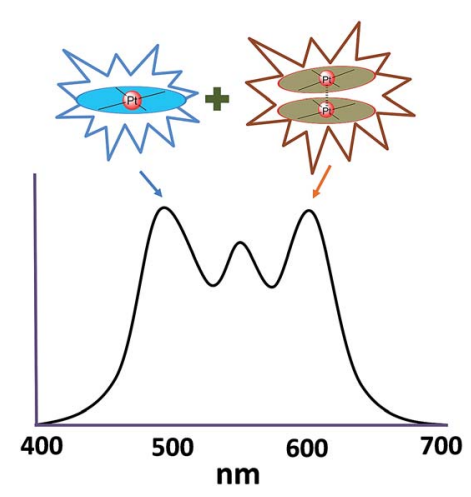

Fig. 8 Schematic illustration of the combination of monomeric emission and excimeric emission to produce white light. 
sterically un-congested ligands, with $\mathbf{5 8}$ as an example, have been prepared; these complexes show both monomeric and excimeric emissions. ${ }^{109}$ Complex 59 exhibits a ${ }^{3} \pi-\pi^{*}\left(\mathrm{O}^{\wedge} \mathrm{N}^{\wedge} \mathrm{C}^{\wedge} \mathrm{N}\right)$ centred bluish-green emission $\left(\lambda_{\max }=482,512 \mathrm{~nm} ; \phi=0.75\right)$ in dilute $\mathrm{CH}_{2} \mathrm{Cl}_{2} \cdot{ }^{90}$ At elevated concentrations (up to $1 \times 10^{-4} \mathrm{M}$ ), the emission intensity at $480-520 \mathrm{~nm}$ decreases with a concomitant increase in excimeric emission with a maximum at $620 \mathrm{~nm}$. An efficient WOLED was fabricated using 59 as a single dopant. The peak EQE, current efficiency, and power efficiency were $16.5 \%, 71.0 \mathrm{~cd} \mathrm{~A}^{-1}$, and $55.8 \mathrm{~lm} \mathrm{~W}^{-1}$, respectively. ${ }^{90}$ Since steric bulkiness of the alkyl chains on the fluorene moiety may affect the intermolecular interactions, the butyl chains in $\mathbf{5 9}$ have been replaced with ethyl chains to facilitate intermolecular interactions in $\mathbf{6 0} .^{37}$ Very recently, the EQE and power efficiency of the vacuum-deposited WOLED singly doped with 60 were reported to be $25.1 \%$ and $55.5 \mathrm{~lm} \mathrm{~W}^{-1}$ respectively in an optimized device structure. ${ }^{93}$ Che and co-workers also examined the EL performances of $\mathbf{5 9}$ and $\mathbf{6 0}$ in solution-processed white polymer OLEDs. A peak EQE, current efficiency, and power efficiency of $9.7 \%, 17.0 \mathrm{~cd} \mathrm{~A} \mathrm{~A}^{-1}$, and $9.1 \mathrm{~lm} \mathrm{~W}^{-1}$, respectively, were observed for $59 .{ }^{90}$ For $\mathbf{6 0}$, the EQE was $12.73 \%$, which slightly decreased to $11.51 \%$ at a high brightness of $1000 \mathrm{~cd} \mathrm{~m}^{-2}$, revealing a very low efficiency roll-off. ${ }^{37}$ The high EQE obtained for vacuum-deposited or solution-processed WOLEDs based on 57-60 suggests that Pt(II) emitters with highly efficient monomeric and excimeric emissions at appropriate energies are highly promising candidate materials for WOLEDs. However, for all WOLEDs singly doped with 57-60, the CIE $(y>0.41)$ and CRI $<80$ revealed an unsatisfactory quality of the white light output. These could be attributed to an insufficiently high energy of the blue monomer emission. Hence, the development of highly efficient deep blue emitting $\mathrm{Pt}(\mathrm{II})$ complexes with structures that favour highly emissive excimer formation is crucial for attaining high-quality singledopant WOLEDs.

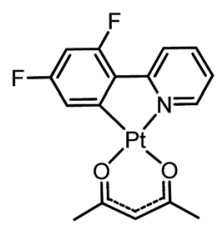

53<smiles>CN1C=CN2c3cccc4c3C(N2C)N41</smiles>

56

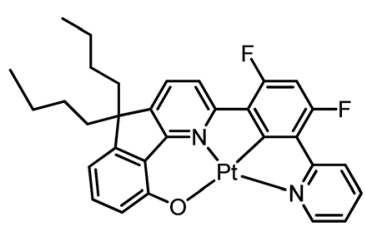

59

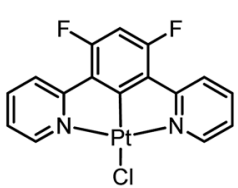

54

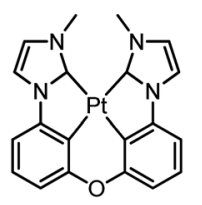

57<smiles></smiles>

55

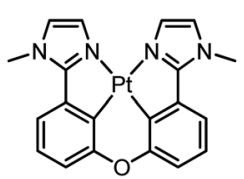

58

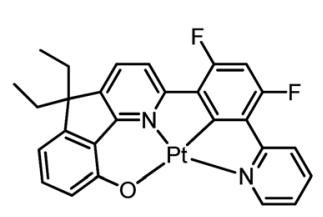

60

\subsection{Self-assembled functional molecular materials}

A subject of growing interest is the self-assembly of phosphorescent Pt(II) complexes into functional molecular materials. This bottom-up approach is illustrated in Scheme 4: (A) selfassembly of Pt(II) complexes into polynuclear aggregates, and (B) further aggregation into quasi-1D nano- or micro-structures (nanowire, nanorod, nanofiber, etc.), ${ }^{\mathbf{1 1 0 - 1 1 6}}$ which can, in certain cases, (C) organize into soft materials such as gels. ${ }^{115,117-122}$ In comparison to the self-assembly of pure organic systems, the presence of phosphorescent $\mathrm{Pt}(\mathrm{II})$ units can provide a spectroscopic handle to follow the self-assembling process based on the high sensitivity of the emission of Pt(II) complexes to Pt $\cdots \mathrm{Pt}$ and $\pi-\pi$ interactions. Furthermore, the presence of $\mathrm{Pt} \cdots \mathrm{Pt}$ and $\mathrm{Pt}(\mathrm{II})$-organic ligand interactions can enhance the stability of the resultant soft material. Due to the luminescent properties and highly ordered stacking arrangements, the resulting Pt(II)superstructures with optoelectronic properties can be used for potential applications in materials science. In this context, we and others have explored the self-assembly behavior of a series of luminescent pincer-type Pt(II) complexes. For instance, we showed that cationic Pt(II) complex 61 can pack in a highly ordered manner with alternate $\mathrm{Pt} \cdot \cdots$ Pt distances of 3.382 and $3.344 \AA$. The nanowires self-assembled from 61 display semiconducting properties and phosphorescence, permitting the

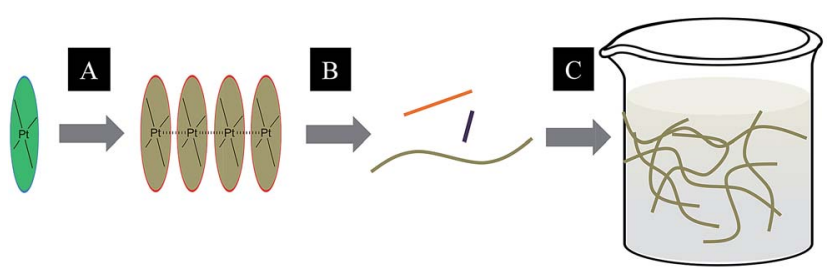

Scheme 4 The illustration of self-assembly of Pt(॥) complexes into 1D nanostructures and soft materials.
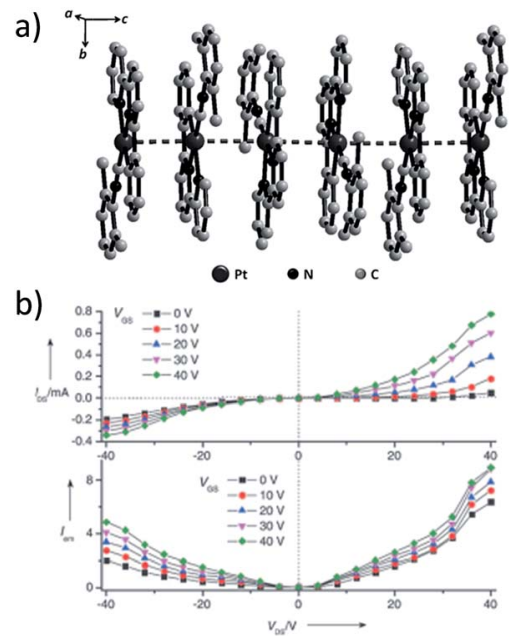

Fig. 9 (a) Crystal packing diagram of $61 \cdot \mathrm{H}_{2} \mathrm{O}$. The $\mathrm{PF}_{6}{ }^{-}$and water molecules are omitted for clarity. (b) Output characteristics (IDS VS. $\left.V_{\mathrm{DS}}\right)$ and electroluminescence intensity $(I)$ of an OLEFET device with nanowires of 61 after annealing at $350 \mathrm{~K}$ (adapted with permission from ref. 112. Copyright 2008, Wiley-VCH Verlag GmbH \& Co. KGaA). 

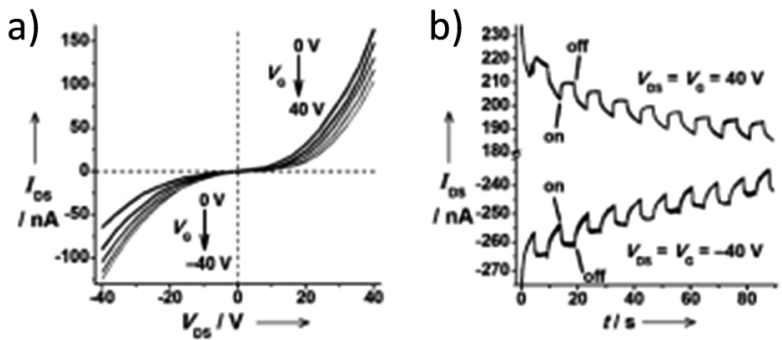

Fig. 10 (a) Output characteristics (IDS vs. $V_{D S}$ ) of a FET device with nanosheets of 66. (b) Transient measurement $\left(V_{D S}=V_{G}= \pm 40 \mathrm{~V}\right)$ of the FET device. The transient channel current was recorded with a 40 $\mathrm{mW} \mathrm{cm}{ }^{-2}$ light switching on and off every five seconds in a 90 second period. $I_{\mathrm{DS}}=$ drain-source current, $V_{\mathrm{DS}}=$ drain-source voltage, $V_{\mathrm{G}}=$ gate voltage (adapted with permission from ref. 123. Copyright 2009, Wiley-VCH Verlag GmbH \& Co. KGaA).

fabrication of organic light-emitting field-effect transistors (OLEFETs) (Fig. 9). ${ }^{112}$ Che and Lu recently reported the synthesis of a strongly emissive $\mathrm{Pt}(\mathrm{II})$ allenylidene complex 63, which was found to form nanorods via self-assembly in $\mathrm{CH}_{3} \mathrm{CN} / \mathrm{H}_{2} \mathrm{O}^{113}$ Interestingly, transformation from nanorods to nanorings upon increasing the water fraction in the solvent mixture was observed. ${ }^{113}$ Charge transport is conceived to be facilitated along highly ordered one-dimensional $\mathrm{Pt} \cdots \mathrm{Pt}$ and $\pi-\pi$ packing chains. A high field-effect electron mobility of up to $20 \mathrm{~cm}^{2} \mathrm{~V}^{-1}$ $\mathrm{s}^{-1}$ was recorded with a transistor fabricated from a single microcrystal of $64 .{ }^{114}$ De Cola and co-workers developed a neutral $\mathrm{Pt}(\mathrm{II})$ emitter, 65, supported by dianionic tridentate terpyridine-like ligand. This complex is non-emissive in dilute solution and undergoes self-assembly to give gelating nanowires accompanied by a striking phosphorescence switch-on $(\phi$ $=0.90) .{ }^{115}$ Apart from the $1 \mathrm{D}$ nano- and micro-structures, Che and co-workers showed that the neutral Pt(II) complex 66 underwent self-assembly into quasi-2D nanosheets driven by the orthogonal $\mathrm{Pt} \cdots \mathrm{Pt}$ and $\mathrm{C}-\mathrm{H} \cdots \pi(\mathrm{C} \equiv \mathrm{C})$ interactions. These nano-sheets showed NIR phosphorescence and visible lightmodulated electronic conductivity (Fig. 10). ${ }^{123}$
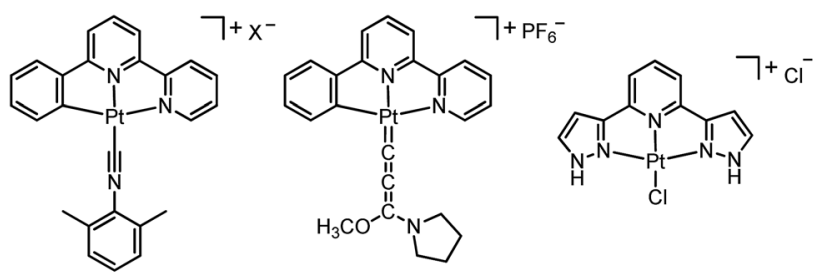

$\mathrm{X}=\mathrm{PF}_{6} 61 ; \mathrm{X}=\mathrm{Cl} 62$

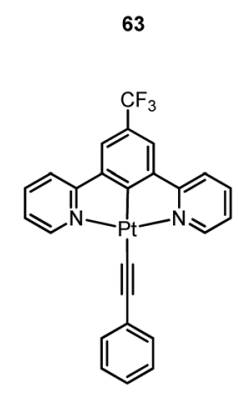

65

66

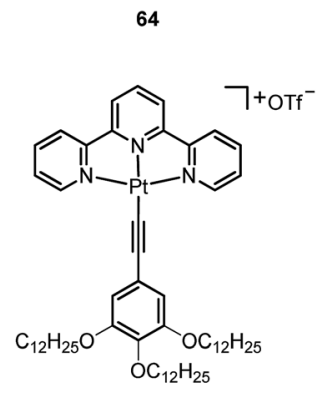

67
Yam and co-workers have extensively studied supramolecular soft materials based on luminescent alkynylplatinum(II) complexes with tridentate N-donor ligands, particularly terpyridine. ${ }^{124}$ It was reported that $\mathbf{6 7}$ can form a metallo-gel in DMSO with a low critical gelation concentration of $4.4 \mathrm{mg} \mathrm{mL}{ }^{-1}{ }^{118}$ Drastic colour and emission changes were observed upon the sol-to-gel transition (Fig. 11a and b), revealing that Pt $\cdots$ Pt and $\pi-\pi$ interactions were involved in the gel formation. Transmission electron microscopy (TEM) and scanning electron microscopy (SEM) images of the xerogel showed a network of fibrous structures with a diameter and length of approximately $470 \mathrm{~nm}$ and $10 \mu \mathrm{m}$, respectively (Fig. 11c and d). Unlike the supramolecular soft materials formed from organic molecules bearing H-bonding motifs and/or long soft alkyl chains, ${ }^{125}$ the Pt $\cdots \mathrm{Pt}$ and $\pi-\pi$ interactions between organoplatinum(II) units provide the driving force for self-assembly. On the other hand, the anion of cationic $\mathrm{Pt}(\mathrm{II})$ complexes has been found to play a crucial role in determining both the extent of intermolecular interactions and the interactions with the solvent medium, thereby providing an entry for tuning the softness of the selfassembled structures. ${ }^{126,127}$ As a result, simple and easy-tosynthesize Pt(II) molecules, not containing H-bonding motifs and long alkyl chains, can be used as building blocks for supramolecular soft materials. For example, 62, an analogue of 61 with a $\mathrm{Cl}^{-}$anion, is soluble in water and was observed to form a chromic meso-phase in water with a critical concentration of $1.5 \mathrm{wt} \%{ }^{119}$

The manipulation of the molecular packing arrangement in the solid state by external mechanical stimuli renders Pt(II) emitters $^{127-131}$ as promising mechanoluminescent (ML) candidates for the development of sensory and data storage materials. We synthesized another new type of luminescent $\mathrm{Pt}(\mathrm{II})$ complex, 68, with tetradentate $\mathrm{O}^{\wedge} \mathrm{N}^{\wedge} \mathrm{N}^{\wedge} \mathrm{C}$ ligands (Scheme S2, ESI $\dagger)$. Complex 68 is an analogue of the $\mathrm{Pt}(\mathrm{II})-\mathrm{O}^{\wedge} \mathrm{N}^{\wedge} \mathrm{C}^{\wedge} \mathrm{N}$ complex 36. Yellow and orange crystal polymorphs of 68 in monoclinic and triclinic forms, respectively, were obtained by

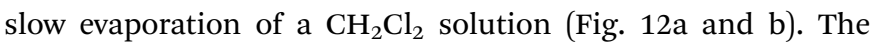

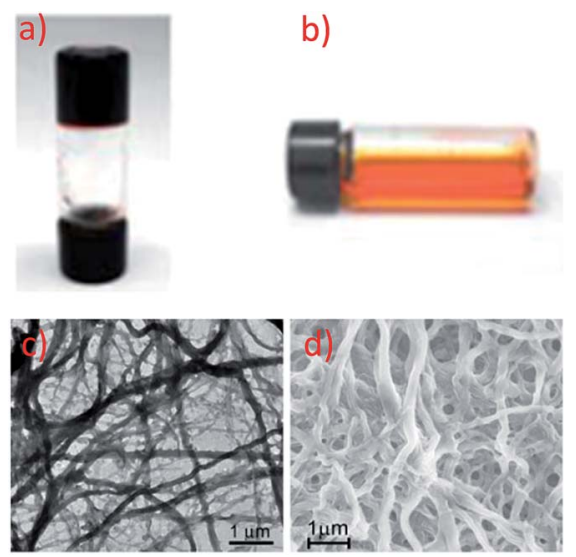

Fig. 11 Photographs of 67 in DMSO in (a) the gel form at room temperature, (b) the sol form at elevated temperature. (c) TEM and (d) SEM images of the xerogel of 67 formed in DMSO (adapted from ref. 118 with permission from the Royal Society of Chemistry). 
intermolecular distances between adjacent molecules in the monoclinic and triclinic crystal forms are 3.524 and $3.468 \AA$, respectively, revealing the presence of weak $\pi-\pi$ interactions. There are no Pt..Pt interactions in either case, since the determined closest Pt $\cdots$ Pt distance is longer than $4.8 \AA$ A. The yellow crystalline solid (triclinic form) precipitated from $\mathrm{CH}_{2} \mathrm{Cl}_{2}$ /hexane displays a vibronic-structured emission $\left(\lambda_{\max }=\right.$ $541,571,621$ (sh) nm). Upon grinding, the emission peak first shifted to $588 \mathrm{~nm}$ and then a broad emission band at $681 \mathrm{~nm}$ was obtained (Fig. 12c and d). This red-shift of emission is probably due to enhanced intermolecular Pt $\cdots \mathrm{Pt}$ and/or $\pi-\pi$ interactions. Addition of $\mathrm{Et}_{2} \mathrm{O}$ or another solvent to the ground solid restored the colour and emission spectrum of the yellow crystalline solid. Interestingly, soaking the ground sample with $\mathrm{Et}_{2} \mathrm{O}$ for about $2 \mathrm{~h}$ resulted in an orange crystalline solid, of which the PXRD pattern was in line with the simulated pattern of the monoclinic crystal form. The interconversions between different forms of $\mathbf{6 8}$ were confirmed by PXRD studies (Fig. S5, ESI $\dagger$ ). To the best of our knowledge, 68 represents the first example of a $\mathrm{Pt}$ (II) complex supported by a tetradentate ligand that shows polymorphic and mechanochromic luminescence properties.

The self-organization of $\mathrm{d}^{8}$ transition metal complexes, such as those of $\mathrm{Rh}(\mathrm{I})$, into luminescent functional assemblies constitutes a fascinating topic within supramolecular chemistry because of their unique photophysical properties imparted by metal $\cdots$ metal interactions. ${ }^{132,133}$ The main driving forces have

a)

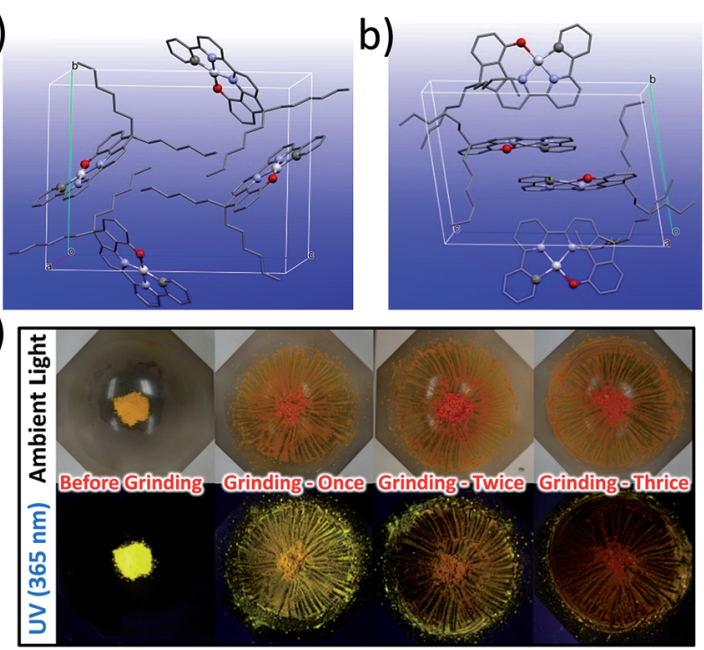

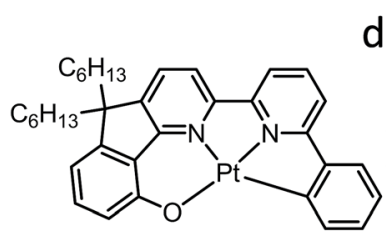

68

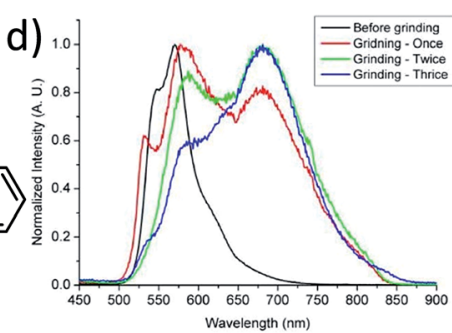

Fig. 12 Crystal packing of 68 in (a) monoclinic form and (b) triclinic form. (c) Photographs of the yellow crystalline solid of 68 before and after grinding under ambient and UV light irradiation (365 $\mathrm{nm}$ ). (d) Emission spectra of 68 (yellow triclinic form) before and after grinding. been generally attributed to the interplay of intermolecular metal $\cdots$ metal and/or $\pi-\pi$ interactions (Scheme 3). ${ }^{\mathbf{1 3 4}}$ In this context, the nature of the intermolecular interactions and the contribution of each interaction component, such as metallophilicity, to the stabilization of aggregates has been an ongoing debate due to the difficulty in accessing relatively highlevel theory for computational studies. ${ }^{\mathbf{1 3 5 - 1 3 9}}$ Recently, a dispersion-corrected DFT method has been shown to be a viable approach to provide a quantitative assessment of the contribution of each interaction component to the intermolecular stabilizing energy of $\mathrm{d}^{8} \mathrm{Rh}(\mathrm{I})$ and $\mathrm{d}^{10} \mathrm{Au}(\mathrm{I})$ dimers. ${ }^{139,140}$ It was shown that the $\mathrm{d}^{8} \cdots \mathrm{d}^{8}$ interactions of $\mathrm{Rh}(\mathrm{I})$ dimers only account for a small fraction (10-15\%) of the dispersion contribution to the total binding energy when $\pi$-conjugated ligands are present. ${ }^{139}$ In the case of relatively large Au(I) systems, the weak ligand-ligand interaction dominates dimer formation. ${ }^{\mathbf{1 4 0}}$ The role of dispersion interactions in driving the self-assembly of luminescent Pt(II) systems has not been studied and its interplay with other weak non-covalent interactions in determining the morphology of the self-assembly structures has not been defined. This prompted us to examine the nature and weight of Pt $\cdots$ Pt interactions by studying the dimer of pincer-type Pt(II) complex 61 which has a strong tendency to aggregate (Fig. 9). ${ }^{112}$ As depicted in Fig. 13, at a Pt..Pt distance of $3.28 \AA$, the dispersive $\mathrm{Pt} \cdots \mathrm{Pt}, \mathrm{Pt} \cdot \cdots$ ligand and ligand $\cdots$ ligand interactions amount to $0.62,6.98$, and $24.81 \mathrm{kcal} \mathrm{mol}^{-1}$, respectively, revealing that the London dispersive attraction dominates the dimer formation of the $\mathrm{Pt}(\mathrm{II})$ molecules.

Inclusion of spin-orbit coupling (SOC) is also essential to understanding the photophysical properties of $\mathrm{d}^{8}-\mathrm{d}^{8}$ diplatinum complexes. Recently, spin-orbit TDDFT (SO-TDDFT) calculations were performed on $\left[\mathrm{Pt}_{2}\left(\mu-\mathrm{P}_{2} \mathrm{O}_{5} \mathrm{H}_{2}\right)_{4}\right]^{4-}$ (abbreviated as $\mathrm{Pt}($ pop $))$ and its perfluoroborated derivative, $\left[\mathrm{Pt}_{2}(\mu\right.$ $\left.\left.\mathrm{P}_{2} \mathrm{O}_{5}\left(\mathrm{BF}_{2}\right)_{2}\right)_{4}\right]^{4-}$ (abbreviated as $\mathrm{Pt}\left(\right.$ pop- $\left.\mathrm{BF}_{2}\right)$ ) to shed light on the ISC mechanism in these complexes. ${ }^{141}$ It was highlighted that the ${ }^{1} \mathrm{~d} \sigma^{*} \mathrm{p} \sigma \rightarrow{ }^{3} \mathrm{~d} \sigma^{*} \mathrm{p} \sigma$ ISC is facilitated by second-order spinorbit coupling with the high-lying ligand-to-metal-metal charge transfer (LMMCT) $d \pi p \sigma$ and $p \pi p \sigma$ excited states. Owing to the calculation results that $\mathrm{Pt}\left(\mathrm{pop}-\mathrm{BF}_{2}\right)$ has a larger energy gap

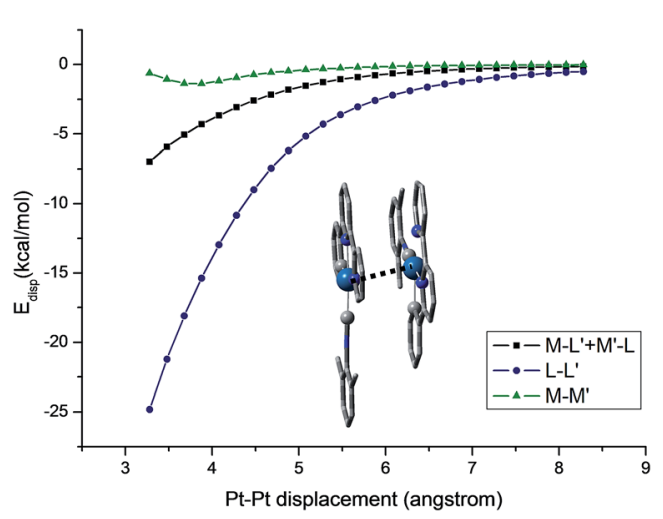

Fig. 13 Dispersion contributions of the metal atoms and ligand fragments to the dimer $\left[61-\mathrm{PF}_{6}\right]_{2}{ }^{2+}$. The $\mathrm{Pt} \cdots \mathrm{Pt}^{\prime}$ distance was used as a reaction coordinate. 
between the $\mathrm{d} \sigma^{*} \mathrm{p} \sigma$ and the LMMCT excited states, $\mathrm{Pt}\left(\mathrm{pop}-\mathrm{BF}_{2}\right)$ has a slower ISC rate than $\mathrm{Pt}(\mathrm{pop})$. It was also proposed that the structural flexibility of Pt(pop) facilitates transient distortions which allows enhanced spin-orbit coupling (SOC) between the ${ }^{1} \mathrm{~d} \sigma^{*} \mathrm{p} \sigma$ and ${ }^{3} \mathrm{~d} \sigma^{*} \mathrm{p} \sigma$ excited states, leading to a much faster ISC rate in $\mathrm{Pt}(\mathrm{pop})$. As a result, $\mathrm{Pt}(\mathrm{pop})$ shows dominant phosphorescent emissions but dual fluorescence-phosphorescence is observed for $\mathrm{Pt}\left(\mathrm{pop}-\mathrm{BF}_{2}\right)$.

\section{Conclusion and outlook}

Multidentate ligands containing strong $\sigma$-donor atoms are advantageous for the construction of robust, phosphorescent $\operatorname{Pt}(\mathrm{II})$ emitters. The strong $\sigma$-donor strength and high rigidity of the ligand scaffold can push the $\mathrm{d}-\mathrm{d}$ states well above the triplet emitting state thereby minimizing excited state structural distortion and non-radiative decay. Due to strong chelate effect, the stability of Pt(II) complexes can be significantly improved with the use of multidentate ligands. Following these design principles, a number of phosphorescent Pt(II) complexes that are photo-stable, kinetically inert and chemically stable under various conditions have been developed. Using terdentate or tetradentate cyclometalating ligands, tremendous progress has been made in tuning the emission energy and emission quantum yield as well as excited state lifetime of $\mathrm{Pt}$ (II) complexes. OLEDs based on luminescent Pt(II) complexes emanating red, yellow, green, or blue light with maximum EQEs higher than $20 \%$ have been reported. The unique excimeric emission from luminescent $\mathrm{Pt}(\mathrm{II})$ complexes has been harnessed in the fabrication of efficient single-dopant WOLEDs. Luminescent Pt(II) complexes have also been shown to have rich photochemistry; for example, they act as efficient photocatalysts for organic transformations. Intermolecular Pt $\cdots \mathrm{Pt}$ and $\pi-\pi$ interactions provide directional driving forces for the anisotropic growth of $1 \mathrm{D}$ or $2 \mathrm{D}$ nano- or microstructures with interesting optoelectronic properties.

The planar coordination geometry also endows the phosphorescent Pt(II) complexes with axial coordination sites for metal-substrate interactions, forming an operating principle for luminescent sensory applications such as cellular imaging. Numerous Pt(II) terpyridyl (trpy) complexes have been recognized to be effective DNA and RNA intercalators, owing to the presence of a planar Pt-trpy moiety that favours $\pi-\pi$ stacking interactions with the base pairs of nucleic acids. ${ }^{\mathbf{1 4 2 , 1 4 3}}$ However, Pt(II) terpyridyl complexes usually suffer from inferior luminescence properties. To circumvent the $\mathrm{d}-\mathrm{d}$ state-induced emission quenching of Pt(II) terpyridyl complexes, physiologically stable luminescent Pt(II) complexes supported by a cyclometalated ligand or tetradentate ligand were developed and studied. ${ }^{\mathbf{1 4 4 - 1 4 6}}$ The binding of these complexes with bio-molecules were observed to induce elevations of emission intensity and/or shifts of emission maxima, as a result of the reduced excited state geometry distortion and/or the formation of new emissive adducts. In this context, the good kinetic stability of $\mathrm{Pt}(\mathrm{II})$ complexes with tetradentate ligands in solution, together with their luminescent properties, makes them highly promising bio-sensors.
Che and co-workers described their molecular design studies of a Pt(II) Schiff base complex 69 containing peripheral amine side chains as a c-myc G-quadruplex DNA binder. ${ }^{147}$ Based on UV-Vis absorption and NMR spectroscopic measurements, this complex is stable in aqueous solution for $72 \mathrm{~h}$ at room temperature. Complex 69 is weakly emissive in aqueous Tris/ $\mathrm{KCl}$ buffer solution. Upon addition of the G4A1 quadruplex DNA, an intense emission at $652 \mathrm{~nm}$ developed and the emission intensity increased 8 -fold at a [G-quadruplex]/[69] ratio $\geq$ 20 (Fig. 14). By absorption titration experiments, the binding constant was determined to be $1.72 \pm 0.26 \mathrm{M}^{-1}$ at $20^{\circ} \mathrm{C}$, which is approximately ten-fold of that with non-quadruplex doublestranded DNA molecules. An external end-stacking mode between 69 and G-quadruplex DNA was suggested based on the findings from NMR titration experiments and molecular modeling studies. To the best of our knowledge, this represents the first system of a Pt(II) complex supported by tetradentate ligands as a luminescent bio-probe.

Complex 70 has been reported to display an intense bluishgreen emission at low concentrations $\left(<10^{-5} \mathrm{M}\right.$ in $\left.\mathrm{CH}_{2} \mathrm{Cl}_{2}\right)\left(\lambda_{\max }\right.$ $=479,510 \mathrm{~nm}$ ) while giving an intense excimeric red emission $\left(\lambda_{\max }=624 \mathrm{~nm}\right)$ at elevated concentrations close to $10^{-4} \mathrm{M}^{37}$ Complex 70 was found to aggregate into micron sized rod-like structures in both organic and aqueous media (Fig. S6, ESI $\dagger$ ). These rods showed a strong red emission under ambient conditions. We examined the cell-imaging properties of $\mathbf{7 0}$. Cervical epithelioid carcinoma (HeLa) cells treated with $\mathbf{7 0}$ initially displayed a strong orange emission, revealing the presence of both monomeric and excimeric emissions from $\mathbf{7 0 .}$ Interestingly, the formation of an emissive rod-aggregate was observed in the cellular environment after a $12 \mathrm{~h}$ treatment with 70. No obvious morphological change was identified after a $24 \mathrm{~h}$ treatment at $10 \mu \mathrm{M}$, suggesting 70 is of low cytotoxicity. The costaining analysis revealed that the complex selectively accumulates in the endoplasmic reticulum (ER) prior to aggregate formation (Fig. 15). Hence, our results show that 70 localizes in ER and subsequently self-assembles into a rod-like morphology. The self-assembled superstructures of luminescent $\mathrm{Pt}(\mathrm{II})$
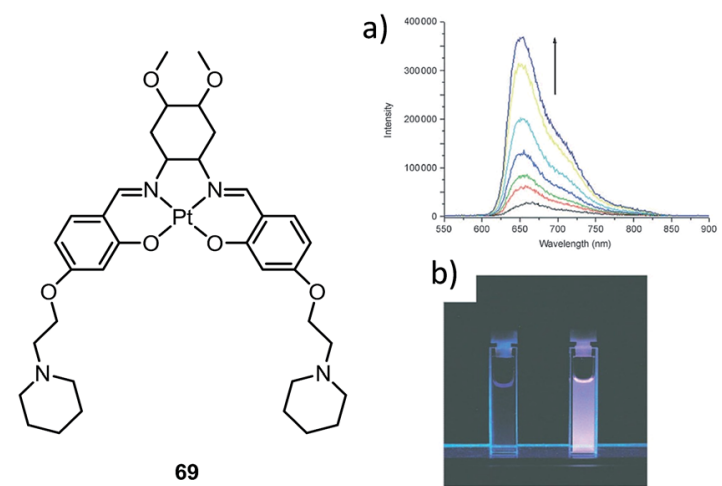

Fig. 14 (a) Emission spectral traces of $69(50 \mu \mathrm{M})$ in Tris/ $\mathrm{KCl}$ buffer with increasing concentrations of G-quadruplex DNA at $20{ }^{\circ} \mathrm{C}$. (b) Photographs of 69 in the absence or the presence of G-quadruplex DNA (adapted with permission from ref. 147. Copyright 2009, WileyVCH Verlag GmbH \& Co. KGaA). 


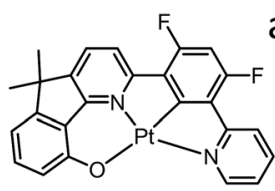

70

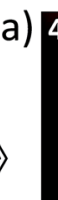

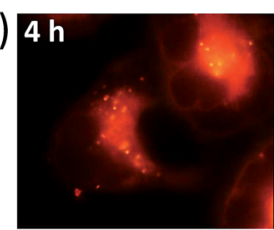

ER
$24 \mathrm{~h}$

8 (1) Cells were treated with $70(5 \mu \mathrm{M})$ for $2 \mathrm{~h}$. in a cellular environment.
Fig. 15 Fluorescence imaging of cells treated with 70. (a) Imaging of HeLa cells treated with $70(5 \mu \mathrm{M})$ for 4 and $24 \mathrm{~h}\left(\lambda_{\mathrm{ex}}=440 \mathrm{~nm} ; \lambda_{\mathrm{em}}>\right.$ $590 \mathrm{~nm}$ ). (b) Co-localization of 70 and ER-RFP (red fluorescent protein) revealed that the complex selectively accumulates in the ER.

complexes have been recently recognized to afford advantages in bioimaging applications because of their stable and persistent emission by shielding oxygen- and solvent moleculeinduced emission quenching, and their more biocompatible low-energy emission. ${ }^{\mathbf{1 4 8 - 1 5 0}}$ Herein, we have demonstrated the application of a highly luminescent $\mathrm{Pt}$ (II) complex with a tetradentate ligand in cell-imaging and, more importantly, the control of the self-assembly behaviour of exogenous molecules

Despite the striking advances that have been made in the development of robust, efficient Pt(II) emitters, there are fundamental issues that need to be resolved prior to their practical applications. These issues include: (1) the limited number of $\mathrm{Pt}$ (II) complexes that display efficient deep blue emission. In view of their importance in full-colour display and white-light illumination and in the design of new strongly oxidizing and reducing excited state species for visible light-driven organic transformations, a deep understanding of the structure-photophysics relationship of, and further development of deep blue emitting Pt(II) complexes are required; (2) the pursuit of stable NIR emitting $\mathrm{Pt}(\mathrm{II})$ complexes for medical applications because of the biocompatibility and high transmittance of NIR photons; (3) the small number of $\mathrm{Pt}(\mathrm{II})$ complexes reported to display efficient excimeric emissions. As the structural features affecting the photophysical properties of excimeric emissions are not well understood, the rational design and exploitation of excimeric emissions of luminescent Pt(II) complexes remains a formidable challenge. Nevertheless, robust and highly phosphorescent Pt(II) complexes would have tremendous applications in diverse disciplines. In addition to OLED applications, the practical utilization of luminescent Pt(II) complexes, supported by tetradentate ligands, as robust cell imaging agents, new photocatalysts, and building blocks for self-assembled functional molecular materials has a bright future.

\section{Note added after first publication}

This article replaces the version published on 7th January 2016, which contained errors in the caption for Fig. 5.

\section{Acknowledgements}

This work was supported by the National Key Basic Research Program of China (No. 2013CB834802), the University Grants Committee (Area of Excellence Scheme AoE/P-03/08), and the Innovation and Technology Commission of the HKSAR Government (ITS/084/14). This work was also supported by the Guangdong Special Project of the Introduction of Innovative R \& D Teams.

\section{Notes and references}

1 A. F. Rausch, H. H. H. Homeier and H. Yersin, Top. Organomet. Chem., 2010, 29, 193.

2 H. Yersin, A. F. Rausch, R. Czerwieniec, T. Hofbeck and T. Fischer, Coord. Chem. Rev., 2011, 255, 2622.

3 K. Kalyanasundaram, Coord. Chem. Rev., 1982, 46, 159.

4 A. Juris, V. Balzani, F. Barigelletti, S. Campagna, P. Belser and A. von Zelewsky, Coord. Chem. Rev., 1988, 84, 85.

5 Y. Chi and P.-T. Chou, Chem. Soc. Rev., 2010, 39, 638.

6 L. Xiao, Z. Chen, B. Qu, J. Luo, S. Kong, Q. Gong and J. Kido, Adv. Mater., 2011, 23, 926.

7 H. Xu, R. Chen, Q. Sun, W. Lai, Q. Su, W. Huang and X. Liu, Chem. Soc. Rev., 2014, 43, 3259.

8 V. H. Houlding and V. M. Miskowski, Coord. Chem. Rev., 1991, 111, 145.

9 S.-W. Lai and C.-M. Che, Top. Curr. Chem., 2004, 241, 27.

10 V. Guerchais and J.-L. Fillaut, Coord. Chem. Rev., 2011, 255, 2448.

11 K. M.-C. Wong and V. W.-W. Yam, Coord. Chem. Rev., 2007, 251, 2477.

12 Q. Zhao, F. Li and C. Huang, Chem. Soc. Rev., 2010, 39, 3007.

13 J. E. McGarrah, Y.-J. Kim, M. Hissler and R. Eisenberg, Inorg. Chem., 2001, 40, 4510.

14 P. Du, J. Schneider, P. Jarosz and R. Eisenberg, J. Am. Chem. Soc., 2006, 128, 7726.

15 D. Zhang, L.-Z. Wu, L. Zhou, X. Han, Q.-Z. Yang, L.-P. Zhang and C.-H. Tung, J. Am. Chem. Soc., 2004, 126, 3440.

16 J.-J. Zhong, Q.-Y. Meng, G.-X. Wang, Q. Liu, B. Chen, K. Feng, C.-H. Tung and L.-Z. Wu, Chem.-Eur. J., 2013, 19, 6443.

17 F. Guo and W. Sun, J. Phys. Chem. B, 2006, 110, 15029.

18 Q. Zhao, C. Huang and F. Li, Chem. Soc. Rev., 2011, 40, 2508.

19 E. Baggaley, J. A. Weinstein and J. A. G. Williams, Coord. Chem. Rev., 2012, 256, 1762.

20 D.-L. Ma, H.-Z. He, K.-H. Leung, D. S.-H. Chan and C.-H. Leung, Angew. Chem., Int. Ed., 2013, 52, 7666.

21 M. P. Coogan and V. Fernández-Moreira, Chem. Commun., 2014, 50, 384.

22 J. Kalinowski, V. Fattori, M. Cocchi and J. A. G. Williams, Coord. Chem. Rev., 2011, 255, 2401.

23 E. Baranoff, S. Suàrez, P. Bugnon, C. Barolo, R. Buscaino, R. Scopelliti, L. Zuppiroli, M. Graetzel and M. K. Nazeeruddin, Inorg. Chem., 2008, 47, 6575.

24 J. M. Fernández-Hernández, C.-H. Yang, J. I. Beltrán, V. Lemaur, F. Polo, R. Fröhlich, J. Cornil and L. De Cola, J. Am. Chem. Soc., 2011, 133, 10543. 
25 E. Baranoff, H. J. Bolink, F. De Angelis, S. Fantacci, D. Di Censo, K. Djellab, M. Grätzel and M. K. Nazeeruddin, Dalton Trans., 2010, 39, 8914.

26 S. Schmidbauer, A. Hohenleutner and B. König, Adv. Mater., 2013, 25, 2114.

27 S. Archer and J. A. Weinstein, Coord. Chem. Rev., 2012, 256, 2530.

28 L. De Cola, F. Barigelletti, V. Balzani, P. Belser, A. von Zelewsky, F. Voegtle, F. Ebmeyer and S. Grammenudi, J. Am. Chem. Soc., 1988, 110, 7210.

29 F. Barigelletti, L. De Cola, V. Balzani, P. Belser, A. von Zelewsky, F. Voegtle, F. Ebmeyer and S. Grammenudi, J. Am. Chem. Soc., 1989, 111, 4662.

30 A. M. Prokhorov, T. Hofbeck, R. Czerwieniec, A. F. Suleymanova, D. N. Kozhevnikov and H. Yersin, J. Am. Chem. Soc., 2014, 136, 9637.

31 G. S. M. Tong and C.-M. Che, Chem.-Eur. J., 2009, 15, 7225.

32 P.-K. Chow, G. Cheng, G. S. M. Tong, W.-P. To, W.-L. Kwong, K.-H. Low, C.-C. Kwok, C. Ma and C.-M. Che, Angew. Chem., Int. Ed., 2015, 54, 2084.

33 F. A. Cotton, G. Wilkinson, C. A. Murillo and M. Bochmann, Advanced Inorganic Chemistry Wiley and Sons, New York, 6th edn, 1999.

34 R. F. Beeston, S. L. Larson and M. C. Fitzgerald, Inorg. Chem., 1989, 28, 4187.

35 H. Duerr, R. Schwarz, C. Andreis and I. Willner, J. Am. Chem. Soc., 1993, 115, 12362.

36 A. Ruggi, M. Berenguel Alonso, D. N. Reinhoudt and A. H. Velders, Chem. Commun., 2010, 46, 6726.

37 G. Cheng, P.-K. Chow, S. C. F. Kui, C.-C. Kwok and C.-M. Che, Adv. Mater., 2013, 25, 6765.

38 L. Chassot, E. Mueller and A. von Zelewsky, Inorg. Chem., 1984, 23, 4249.

39 L. Chassot and A. von Zelewsky, Inorg. Chem., 1987, 26, 2814.

40 D. Sandrini, M. Maestri, V. Balzani, L. Chassot and A. von Zelewsky, J. Am. Chem. Soc., 1987, 109, 7720.

41 J. Brooks, Y. Babayan, S. Lamansky, P. I. Djurovich, I. Tsyba, R. Bau and M. E. Thompson, Inorg. Chem., 2002, 41, 3055.

42 S. Huo, J. Carroll and D. A. K. Vezzu, Asian J. Org. Chem., 2015, 4, 1210.

43 S.-Y. Chang, Y.-M. Cheng, Y. Chi, Y.-C. Lin, C.-M. Jiang, G.-H. Lee and P.-T. Chou, Dalton Trans., 2008, 6901.

44 S.-W. Lai, M. C.-W. Chan, T.-C. Cheung, S.-M. Peng and C.-M. Che, Inorg. Chem., 1999, 38, 4046.

45 W. Lu, B.-X. Mi, M. C. W. Chan, Z. Hui, C.-M. Che, N. Zhu and S.-T. Lee, J. Am. Chem. Soc., 2004, 126, 4958.

46 S. C. F. Kui, I. H. T. Sham, C. C. C. Cheung, C.-W. Ma, B. Yan, N. Zhu, C.-M. Che and W.-F. Fu, Chem.-Eur. J., 2007, 13, 417.

47 B.-P. Yan, C. C. C. Cheung, S. C. F. Kui, H.-F. Xiang, V. A. L. Roy, S.-J. Xu and C.-M. Che, Adv. Mater., 2007, 19, 3599.

48 C.-L. Ho, H. Li and W.-Y. Wong, J. Organomet. Chem., 2014, 751, 261.

49 Q. Xu, W.-f. Fu, G. Zhang, Z. Bian, J. Zhang, X. Han and W. Xu, Catal. Commun., 2008, 10, 49.
50 D. Ravindranathan, D. A. K. Vezzu, L. Bartolotti, P. D. Boyle and S. Huo, Inorg. Chem., 2010, 49, 8922.

51 J. A. G. Williams, A. Beeby, E. S. Davies, J. A. Weinstein and C. Wilson, Inorg. Chem., 2003, 42, 8609.

52 D. J. Cárdenas, A. M. Echavarren and M. C. Ramírez de Arellano, Organometallics, 1999, 18, 3337.

53 S. J. Farley, D. L. Rochester, A. L. Thompson, J. A. K. Howard and J. A. G. Williams, Inorg. Chem., 2005, 44, 9690.

54 E. Rossi, L. Murphy, P. L. Brothwood, A. Colombo, C. Dragonetti, D. Roberto, R. Ugo, M. Cocchi and J. A. G. Williams, J. Mater. Chem., 2011, 21, 15501.

55 E. Rossi, A. Colombo, C. Dragonetti, D. Roberto, F. Demartin, M. Cocchi, P. Brulatti, V. Fattori and J. A. G. Williams, Chem. Commun., 2012, 48, 3182.

56 A. F. Rausch, L. Murphy, J. A. G. Williams and H. Yersin, Inorg. Chem., 2012, 51, 312.

57 W. Mroz, C. Botta, U. Giovanella, E. Rossi, A. Colombo, C. Dragonetti, D. Roberto, R. Ugo, A. Valore and J. A. G. Williams, J. Mater. Chem., 2011, 21, 8653.

58 L. Murphy, P. Brulatti, V. Fattori, M. Cocchi and J. A. G. Williams, Chem. Commun., 2012, 48, 5817.

59 M. Maestri, C. Deuschel-Cornioley and A. von Zelewsky, Coord. Chem. Rev., 1991, 111, 117.

60 V. W.-W. Yam, R. P.-L. Tang, K. M.-C. Wong, X.-X. Lu, K.-K. Cheung and N. Zhu, Chem.-Eur. J., 2002, 8, 4066.

61 W. Lu, M. C. W. Chan, K.-K. Cheung and C.-M. Che, Organometallics, 2001, 20, 2477.

62 S. C. F. Kui, S. S.-Y. Chui, C.-M. Che and N. Zhu, J. Am. Chem. Soc., 2006, 128, 8297.

63 J. R. Berenguer, E. Lalinde and J. Torroba, Inorg. Chem., 2007, 46, 9919.

64 S. Fuertes, S. K. Brayshaw, P. R. Raithby, S. Schiffers and M. R. Warren, Organometallics, 2011, 31, 105.

65 S. C. F. Kui, F.-F. Hung, S.-L. Lai, M.-Y. Yuen, C.-C. Kwok, K.-H. Low, S. S.-Y. Chui and C.-M. Che, Chem.-Eur. J., 2012, 18, 96.

66 M. Ikai, F. Ishikawa, N. Aratani, A. Osuka, S. Kawabata, T. Kajioka, H. Takeuchi, H. Fujikawa and Y. Taga, Adv. Funct. Mater., 2006, 16, 515.

67 C. Borek, K. Hanson, P. I. Djurovich, M. E. Thompson, K. Aznavour, R. Bau, Y. Sun, S. R. Forrest, J. Brooks, L. Michalski and J. Brown, Angew. Chem., Int. Ed., 2007, 46, 1109.

68 J. R. Sommer, A. H. Shelton, A. Parthasarathy, I. Ghiviriga, J. R. Reynolds and K. S. Schanze, Chem. Mater., 2011, 23, 5296.

69 K. R. Graham, Y. Yang, J. R. Sommer, A. H. Shelton, K. S. Schanze, J. Xue and J. R. Reynolds, Chem. Mater., 2011, 23, 5305.

70 Y.-Y. Lin, S.-C. Chan, M. C. W. Chan, Y.-J. Hou, N. Zhu, C.-M. Che, Y. Liu and Y. Wang, Chem.-Eur. J., 2003, 9, 1263.

71 C.-M. Che, S.-C. Chan, H.-F. Xiang, M. C. W. Chan, Y. Liu and Y. Wang, Chem. Commun., 2004, 1484.

72 C.-M. Che, C.-C. Kwok, S.-W. Lai, A. F. Rausch, W. J. Finkenzeller, N. Zhu and H. Yersin, Chem.-Eur. J., 2010, 16, 233. 
73 G. S. M. Tong, P. K. Chow, W.-P. To, W.-M. Kwok and C.-M. Che, Chem.-Eur. J., 2014, 20, 6433.

74 L. Zhou, C.-L. Kwong, C.-C. Kwok, G. Cheng, H. Zhang and C.-M. Che, Chem.-Asian J., 2014, 9, 2984.

75 J. Zhang, F. Zhao, X. Zhu, W.-K. Wong, D. Ma and W.-Y. Wong, J. Mater. Chem., 2012, 22, 16448.

76 H.-F. Xiang, S.-C. Chan, K. K.-Y. Wu, C.-M. Che and P. T. Lai, Chem. Commun., 2005, 1408.

77 F. Nisic, A. Colombo, C. Dragonetti, D. Roberto, A. Valore, J. M. Malicka, M. Cocchi, G. R. Freeman and J. A. G. Williams, J. Mater. Chem. C, 2014, 2, 1791.

78 K.-Y. Liao, C.-W. Hsu, Y. Chi, M.-K. Hsu, S.-W. Wu, C.-H. Chang, S.-H. Liu, G.-H. Lee, P.-T. Chou, Y. Hu and N. Robertson, Inorg. Chem., 2015, 54, 4029.

79 K. Feng, C. Zuniga, Y.-D. Zhang, D. Kim, S. Barlow, S. R. Marder, J. L. Brédas and M. Weck, Macromolecules, 2009, 42, 6855.

80 D. A. K. Vezzu, J. C. Deaton, J. S. Jones, L. Bartolotti, C. F. Harris, A. P. Marchetti, M. Kondakova, R. D. Pike and S. Huo, Inorg. Chem., 2010, 49, 5107.

81 H. Fukagawa, T. Shimizu, H. Hanashima, Y. Osada, M. Suzuki and H. Fujikake, Adv. Mater., 2012, 24, 5099.

82 A. Tsuboyama, H. Iwawaki, M. Furugori, T. Mukaide, J. Kamatani, S. Igawa, T. Moriyama, S. Miura, T. Takiguchi, S. Okada, M. Hoshino and K. Ueno, J. Am. Chem. Soc., 2003, 125, 12971.

83 D. H. Kim, N. S. Cho, H.-Y. Oh, J. H. Yang, W. S. Jeon, J. S. Park, M. C. Suh and J. H. Kwon, Adv. Mater., 2011, 23, 2721.

84 C.-H. Fan, P. Sun, T.-H. Su and C.-H. Cheng, Adv. Mater., 2011, 23, 2981.

85 S. Huo, C. F. Harris, D. A. K. Vezzu, J. P. Gagnier, M. E. Smith, R. D. Pike and Y. Li, Polyhedron, 2013, 52, 1030. 86 J. V. Caspar and T. J. Meyer, J. Phys. Chem., 1983, 87, 952.

87 K. Li, X. Guan, C.-W. Ma, W. Lu, Y. Chen and C.-M. Che, Chem. Commun., 2011, 47, 9075.

88 A. Meyer, Y. Unger, A. Poethig and T. Strassner, Organometallics, 2011, 30, 2980.

89 K. Li, G. Cheng, C. Ma, X. Guan, W.-M. Kwok, Y. Chen, W. Lu and C.-M. Che, Chem. Sci., 2013, 4, 2630.

90 S. C. F. Kui, P. K. Chow, G. S. M. Tong, S.-L. Lai, G. Cheng, C.-C. Kwok, K.-H. Low, M. Y. Ko and C.-M. Che, Chem.-Eur. J., 2013, 19, 69.

91 S. C. F. Kui, P. K. Chow, G. Cheng, C.-C. Kwok, C. L. Kwong, K.-H. Low and C.-M. Che, Chem. Commun., 2013, 49, 1497.

92 S.-L. Lai, W.-Y. Tong, S. C. F. Kui, M.-Y. Chan, C.-C. Kwok and C.-M. Che, Adv. Funct. Mater., 2013, 23, 5168.

93 G. Cheng, S. C. F. Kui, W.-H. Ang, M.-Y. Ko, P.-K. Chow, C.-L. Kwong, C.-C. Kwok, C. Ma, X. Guan, K.-H. Low, S.-J. Su and C.-M. Che, Chem. Sci., 2014, 5, 4819.

94 X.-C. Hang, T. Fleetham, E. Turner, J. Brooks and J. Li, Angew. Chem., Int. Ed., 2013, 52, 6753.

95 E. Turner, N. Bakken and J. Li, Inorg. Chem., 2013, 52, 7344. 96 T. Fleetham, G. Li, L. Wen and J. Li, Adv. Mater., 2014, 26, 7116.

97 G. Li, T. Fleetham, E. Turner, X.-C. Hang and J. Li, Adv. Opt. Mater., 2015, 3, 390.
98 J. A. Bailey, V. M. Miskowski and H. B. Gray, Inorg. Chem., 1993, 32, 369.

99 J. A. Bailey, M. G. Hill, R. E. Marsh, V. M. Miskowski, W. P. Schaefer and H. B. Gray, Inorg. Chem., 1995, 34, 4591.

100 H.-K. Yip, C.-M. Che, Z.-Y. Zhou and T. C. W. Mak, J. Chem. Soc., Chem. Commun., 1992, 1369.

101 V. M. Miskowski and V. H. Houlding, Inorg. Chem., 1991, 30, 4446.

102 V. M. Miskowski and V. H. Houlding, Inorg. Chem., 1989, 28, 1529.

103 B. W. D'Andrade and S. R. Forrest, Adv. Mater., 2004, 16, 1585.

104 V. Adamovich, J. Brooks, A. Tamayo, A. M. Alexander, P. I. Djurovich, B. W. D'Andrade, C. Adachi, S. R. Forrest and M. E. Thompson, New J. Chem., 2002, 26, 1171.

105 E. L. Williams, K. Haavisto, J. Li and G. E. Jabbour, Adv. Mater., 2007, 19, 197.

106 X. Yang, Z. Wang, S. Madakuni, J. Li and G. E. Jabbour, Adv. Mater., 2008, 20, 2405.

107 T. Fleetham, J. Ecton, Z. Wang, N. Bakken and J. Li, Adv. Mater., 2013, 25, 2573.

108 G. Li, T. Fleetham and J. Li, Adv. Mater., 2014, 26, 2931.

109 T. Fleetham, L. Huang and J. Li, Adv. Funct. Mater., 2014, 24, 6066.

110 Y. Sun, K. Ye, H. Zhang, J. Zhang, L. Zhao, B. Li, G. Yang, B. Yang, Y. Wang, S.-W. Lai and C.-M. Che, Angew. Chem., Int. Ed., 2006, 45, 5610.

111 W. Lu, V. A. L. Roy and C.-M. Che, Chem. Commun., 2006, 3972.

112 M.-Y. Yuen, V. A. L. Roy, W. Lu, S. C. F. Kui, G. S. M. Tong, M.-H. So, S. S.-Y. Chui, M. Muccini, J. Q. Ning, S. J. Xu and C.-M. Che, Angew. Chem., Int. Ed., 2008, 47, 9895.

113 X.-S. Xiao, W.-L. Kwong, X. Guan, C. Yang, W. Lu and C.-M. Che, Chem.-Eur. J., 2013, 19, 9457.

114 C.-M. Che, C.-F. Chow, M.-Y. Yuen, V. A. L. Roy, W. Lu, Y. Chen, S. S.-Y. Chui and N. Zhu, Chem. Sci., 2011, 2, 216.

115 C. A. Strassert, C.-H. Chien, M. D. Galvez Lopez, D. Kourkoulos, D. Hertel, K. Meerholz and L. De Cola, Angew. Chem., Int. Ed., 2011, 50, 946.

116 M. Mauro, A. Aliprandi, C. Cebrian, D. Wang, C. Kubel and L. De Cola, Chem. Commun., 2014, 50, 7269.

117 F. Camerel, R. Ziessel, B. Donnio, C. Bourgogne, D. Guillon, M. Schmutz, C. Iacovita and J.-P. Bucher, Angew. Chem., Int. Ed., 2007, 46, 2659.

118 A. Y.-Y. Tam, K. M.-C. Wong, G. Wang and V. W.-W. Yam, Chem. Commun., 2007, 2028.

119 W. Lu, Y. Chen, V. A. L. Roy, S. S.-Y. Chui and C.-M. Che, Angew. Chem., Int. Ed., 2009, 48, 7621.

120 X.-S. Xiao, W. Lu and C.-M. Che, Chem. Sci., 2014, 5, 2482.

121 N. K. Allampally, C. A. Strassert and L. De Cola, Dalton Trans., 2012, 41, 13132.

122 J. Wang, Y. Chen, Y.-C. Law, M. Li, M.-X. Zhu, W. Lu, S. S.-Y. Chui, N. Zhu and C.-M. Che, Chem.-Asian J., 2011, 6, 3011.

123 Y. Chen, K. Li, W. Lu, S. S.-Y. Chui, C.-W. Ma and C.-M. Che, Angew. Chem., Int. Ed., 2009, 48, 9909. 
124 A. Y.-Y. Tam and V. W.-W. Yam, Chem. Soc. Rev., 2013, 42, 1540.

125 A. R. Hirst, B. Escuder, J. F. Miravet and D. K. Smith, Angew. Chem., Int. Ed., 2008, 47, 8002.

126 V. W.-W. Yam, K. H.-Y. Chan, K. M.-C. Wong and N. Zhu, Chem.-Eur. J., 2005, 11, 4535.

127 M. Krikorian, S. Liu and T. M. Swager, J. Am. Chem. Soc., 2014, 136, 2952.

128 J. Ni, X. Zhang, Y.-H. Wu, L.-Y. Zhang and Z.-N. Chen, Chem.-Eur. J., 2011, 17, 1171.

129 L.-M. Huang, G.-M. Tu, Y. Chi, W.-Y. Hung, Y.-C. Song, M.-R. Tseng, P.-T. Chou, G.-H. Lee, K.-T. Wong, S.-H. Cheng and W.-S. Tsai, J. Mater. Chem. C, 2013, 1, 7582.

130 V. N. Kozhevnikov, B. Donnio and D. W. Bruce, Angew. Chem., Int. Ed., 2008, 47, 6286.

131 X. Zhang, Z. Chi, Y. Zhang, S. Liu and J. Xu, J. Mater. Chem. C, 2013, 1, 3376.

132 K. R. Mann, J. G. Gordon and H. B. Gray, J. Am. Chem. Soc., 1975, 97, 3553.

133 Y. Chen, K. Li, H. O. Lloyd, W. Lu, S. S.-Y. Chui and C.-M. Che, Angew. Chem., Int. Ed., 2010, 49, 9968.

134 V. W.-W. Yam, V. K.-M. Au and S. Y.-L. Leung, Chem. Rev., 2015, 115, 7589.

135 P. Pyykkö and Y. Zhao, Angew. Chem., Int. Ed., 1991, 30, 604. 136 P. Pyykkö and F. Mendizabal, Chem.-Eur. J., 1997, 3, 1458.

137 L. Magnko, M. Schweizer, G. Rauhut, M. Schutz, H. Stoll and H.-J. Werner, Phys. Chem. Chem. Phys., 2002, 4, 1006.
138 J. Muñiz, C. Wang and P. Pyykkö, Chem.-Eur. J., 2011, 17, 368.

139 S. Grimme and J.-P. Djukic, Inorg. Chem., 2011, 50, 2619.

140 M. Andrejić and R. A. Mata, Phys. Chem. Chem. Phys., 2013, 15, 18115.

141 S. Záliš, Y.-C. Lam, H. B. Gray and A. Vlček, Inorg. Chem., 2015, 54, 3491.

142 D. R. McMillin and J. J. Moore, Coord. Chem. Rev., 2002, 229, 113.

143 S. D. Cummings, Coord. Chem. Rev., 2009, 253, 1495.

144 P. Wu, E. L.-M. Wong, D.-L. Ma, G. S. M. Tong, K.-M. Ng and C.-M. Che, Chem.-Eur. J., 2009, 15, 3652.

145 T. Zou, J. Liu, C. T. Lum, C. Ma, R. C.-T. Chan, C.-N. Lok, W.-M. Kwok and C.-M. Che, Angew. Chem., Int. Ed., 2014, 53, 10119.

146 D.-L. Ma, C.-M. Che and S.-C. Yan, J. Am. Chem. Soc., 2009, 131, 1835.

147 P. Wu, D.-L. Ma, C.-H. Leung, S.-C. Yan, N. Zhu, R. Abagyan and C.-M. Che, Chem.-Eur. J., 2009, 15, 13008.

148 C.-N. Lok, T. Zou, J.-J. Zhang, I. W.-S. Lin and C.-M. Che, Adv. Mater., 2014, 26, 5550.

149 D. Septiadi, A. Aliprandi, M. Mauro and L. De Cola, $R S C$ $A d v .$, 2014, 4, 25709.

150 M. Mauro, A. Aliprandi, D. Septiadi, N. S. Kehr and L. De Cola, Chem. Soc. Rev., 2014, 43, 4144. 